\title{
Charitable Giving: How Ego-Threats Impact Donations of Time and Money
}

\author{
Rod Duclos
}

A dissertation submitted to the faculty of the University of North Carolina at Chapel Hill in partial fulfillment of the requirements for the degree of Doctor of Philosophy in the KenanFlagler Business School (Marketing).

Chapel Hill

2008

Approved by: Gary Armstrong

Jim Bettman

Paul Bloom

Charlotte Mason

Gal Zauberman 
(C) 2008

Rod Duclos

ALL RIGHTS RESERVED 


\begin{abstract}
Rod Duclos: Charitable Giving: How Ego-Threats Impact Donations of Time and Money (Under the direction of Gary Armstrong, Jim Bettman, Paul Bloom, Charlotte Mason, and Gal Zauberman)

Consumers can exhibit charitableness in a variety of ways, e.g., by reading to the blind, serving food to the hungry, donating money to the needy, etc. Broadly speaking, however, donation behavior can take one of two forms: One can volunteer time or money. Across four experiments, we examine how and why ego-threats, i.e., menaces to one's sense of self and identity, can help foster charitable behavior and lead consumers to prefer donating time over money to their favorite charities. We conclude by discussing the implications of our findings for theory and practice.
\end{abstract}




\section{Acknowledgements}

Along my advisors, I thank Dan Ariely, Dennis Batres, Laura Edwards, Gavan Fitzsimons, Bibb Latané, and Yasmine Redman. 
Table of Contents

Page

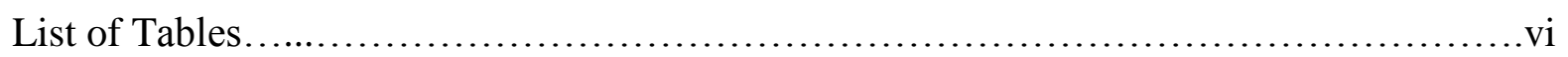

List of Figures...............................................................

List of Appendices...........................................................

Charitable Giving: How Ego-Threats Impact Donations of Time and Money..................1

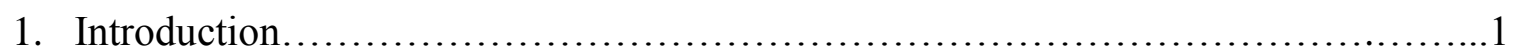

2. Theoretical framework...................................................

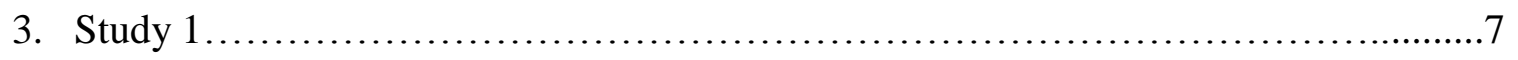

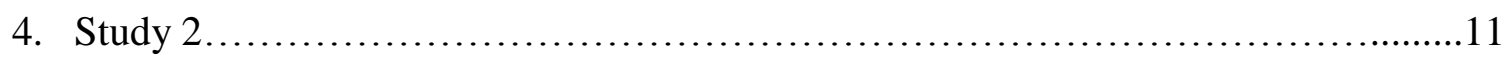

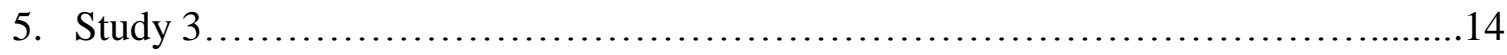

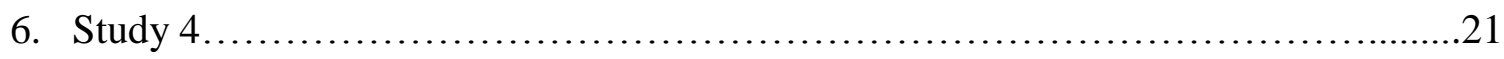

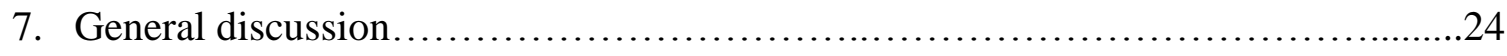

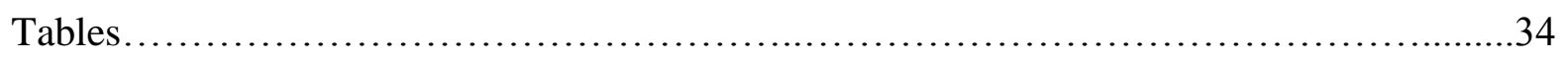

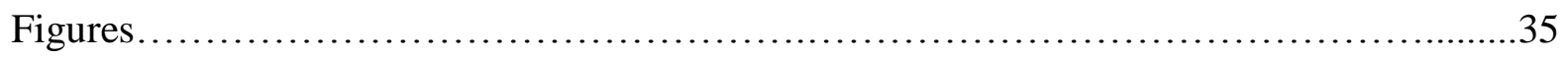

Appendices..................................................................... 39

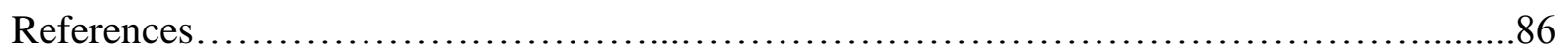




\section{List of Tables}

\section{Table}

1. Total Variance Explained and Factor Loadings (study 3) ........................... 34 


\section{List of Figures}

\section{Figures}

1. State self-esteem following affirmation procedure (study 3 )...................... 35

2. Relative preference between donating $\$ 10$ and 8 hours (study 3 )..................36

3. Relative preference between donating money and time (study 4 )...................37

4. Relative preference between donating money and time (follow up study B)..........38 


\section{List of Appendices}

Appendices

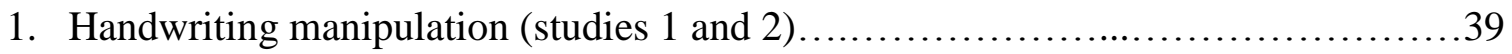

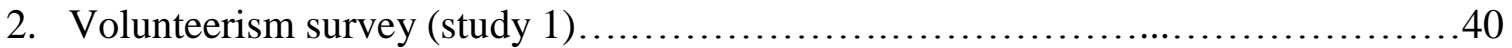

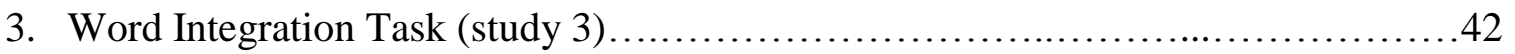

4. Heatherton \& Polivy's (1991) scale of state self-esteem (study 3)..................45

5. Self-affirmation procedure - No self-affirmation condition (study 3 ).............46

6. Self-affirmation procedure -Self-affirmation condition (study 3 ).................47

7. Robins et al.'s (2001) measure of state self-esteem (study 3 )...................48

8. Picture study - Threat condition for women (study 4) ........................49

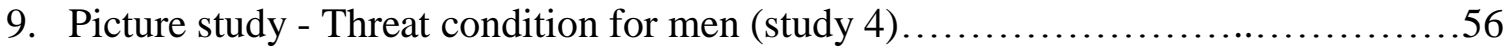

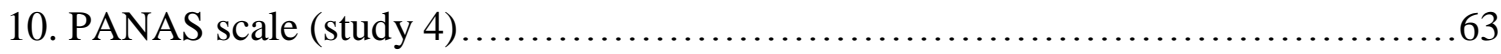

11. Contingencies of self-worth scale by Crocker et al. (2003; study 4)...............64

12. Pictures in advertising - Control condition (follow-up study A) .................66

13. Pictures in advertising - Negative mood condition (follow-up study A)...........67

14. Rosenberg's (1965) scale of state self-esteem (follow up study A)...............68

15. Word Integration Task - Control condition (follow up study B)...............69

16. Word Integration Task - Threat condition (follow up study B) ...................71

17. Peterson \& Sauber's (1983) mood short form (follow up study B).................73

18. Big Brothers Big Sisters Survey - Neutral condition (follow up study B)...........74

19. Big Brothers Big Sisters Survey - Repair condition (follow up study B)............80 


\section{Introduction}

Consumers can exhibit charitableness in a variety of ways, e.g., by reading to the blind, serving food to the hungry, donating money to the needy, etc. Broadly speaking, however, donation behavior can take one of two forms: One can volunteer time or money. Collectively, Americans donate $\$ 260$ billion a year to charities (American Association of Fundraising Counsel 2006) and volunteer an additional 15.5 billion hours of work (Independent Sector 2001). Together these time and monetary contributions amount to nearly half a trillion dollars a year (AAFC 2006; IS 2001). The spectrum of causes served is wide. Animals, the arts, education, public health, the environment: all have organizations and people working to promote their condition and protect their interests. But despite the amplitude of these numbers and the pervasiveness of donation behaviors, the determinants of charitable giving are not well understood (Kottasz 2004). And even less understood are the factors influencing one's decision to donate time versus money (Reed, Aquino, \& Levy 2007a). Yet, considering that some nonprofits rely predominantly on the time donated by volunteers to fulfill their mission (e.g., Meals on Wheels, Habitat for Humanity, Big Brothers Big Sisters) while others do so thanks to generous financial contributions by consumers (e.g., The Christian Children's Fund, The Wildlife Conservation Society, The Mayo Clinic), it seems that identifying the factors influencing donor orientation between volunteerism and financial philanthropy would constitute an important marketing issue. Indeed, with a better understanding of donor psychology, charitable organizations may be able to design better 
communication campaigns and retention programs for their donors and volunteers, two of the most critical challenges nonprofits face today (West 2004).

From a theory perspective, too, gaining a better understanding of the psychological processes underlying consumers' decisions between these two forms of donation behavior would enrich the current state of the literature. Indeed, while much work in economics has focused on financial philanthropy (Andreoni 2004; Harbaugh 1998a, 1998b), and even more work in psychology and sociology has examined volunteerism (Clary et al. 1998; Houle, Sagarin, \& Kaplan 2005; Wilson \& Musick 1997; Wilson 2000), only two papers, to date, have attempted to look at both time and money simultaneously (Reed et al. 2007a, 2007b). Reed and his coauthors show that personality traits such as moral identity, i.e., one's conception of how moral one is, can play a key role in driving one's preference for donating time vs. money. The present research extends Reed et al's (2007a, 2007b) work on personal dispositions by examining how and why ego-threats, i.e., instances where one's self-view is momentarily called into question by external agents or events, can help foster charitable behavior and lead individuals to prefer donating time over money to their favorite charities.

\section{Theoretical framework}

On any given day, consumers face a multitude of situations with the potential to threaten their sense of self as being good, virtuous, or successful (Sherman \& Cohen 2006; Steele 1988). A few examples of such situations include substandard performance on the job or in class, frustrated goals or aspirations, information challenging the validity of long held beliefs, the defeat of one's political party in an election or of one's favorite sports team in a playoff, rejection in a romantic relationship, etc. In response to such ego-threats, consumers can engage in one of three behaviors. First, they can acknowledge their failure and use it for 
attitudinal or behavioral change. Research in social psychology, however, has shown that such a course of action isn't always likely. Indeed, insofar as the threat encountered pertains to an important aspect of one's identity, the need to maintain self-esteem can make it difficult to accept the threatening information and to change one's attitude or behavior accordingly (Sherman \& Cohen 2006). A second course of action is to dismiss, deny, derogate, or altogether avoid the threat and its source (Sherman \& Cohen 2002). Though such a defensive response may protect self-esteem in the short run, ignoring threatening information is maladaptive in the long run as it jeopardizes one's chances to learn and grow from potentially critical feedback (Sherman \& Cohen 2006). Self-affirmation, the third course of action, constitutes the basis of our investigation.

According to self-affirmation theory (Steele \& Liu 1983, Steele 1988, Steele, Spencer, \& Lynch 1993), one of the self's major considerations consists of maintaining a perception of global integrity, that is, of overall moral and adaptive adequacy. Selfaffirmation can then be seen as an image-restoration process triggered whenever something in the environment, or in one's own behavior, threatens one's self-image. Since the goal of the system is to maintain an overall image of self-integrity, the self does not need to confront every attack emanating from the environment. Indeed, one may opt to leave certain threats untreated to instead affirm some other important self-concept, thereby reinforcing overall self-adequacy. In 1991, Tesser \& Cornell provided a compelling demonstration of selfaffirmation flexibility. Adapting Steele \& Liu's (1983) original paradigm, they showed that self-image distress resulting from an unfavorable social comparison could be relieved by recalling a favorable social experience of a different sort. 
In light of these findings, we propose that by affirming a generous and/or compassionate dimension of the self, volunteerism, and to some extent financial philanthropy, may also serve a self-affirmation function for the threatened self. In most cultures, indeed, generosity and compassion are regarded as admirable qualities. Helping those in need is, for instance, a recurring theme in the bible: "When you reap the harvest of your land, you shall not reap to the very edges of your field, nor shall you gather the gleanings of your harvest. You shall not strip your vineyard bare, or gather the fallen grapes of your vineyard; you shall leave them for the poor and the alien: I am the LORD your God" (NRSV, Leviticus 19:9-10). Therefore, exhibiting charitableness may procure the injured self an opportunity to self-affirm by either fulfilling a religious duty or adhering to a sociallypraised custom.

The psychology of time and money

From a pure economics perspective, one would expect consumers to be indifferent between volunteering time and money to charities. Assuming, indeed, that a charity has no preference for receiving time or money contributions (i.e., the charity can benefit equally from either gift kind), a consumer who estimates one hour of his time to be worth $\$ 20$ should find himself equally likely to volunteer $\$ 100$ or five hours. Yet, a growing body of research in sociology, psychology, and marketing provides evidence departing from the above argument. In this section, we review these literatures to highlight how and why donating money versus time may not follow traditional economics principles. In doing so, we provide the foundation for our own hypothesis that volunteerism offers greater repair potential to the threatened self than financial philanthropy. 
Why might consumers favor donating their time rather than an equivalent amount of money? One possible rationale is suggested in recent work by Zauberman \& Lynch (2005) that demonstrates a common forecasting bias among consumers. Indeed, while consumers can be fairly accurate at predicting the amount of financial resources they will have available in the future, they become quite inaccurate when predicting their future availability of time. This over-prediction of the availability of time vs. money may thus be one reason why consumers would favor donating time over money when asked to commit help in the distant future. Yet, what would explain such a preference when the commitment to help is proximal in time?

Recent work by Liu \& Aaker (2008) proposing that time and money activate different mindsets in consumers may help answer this question. According to associative memory theory (Anderson \& Bower 1973), individuals store the knowledge, goals, and concepts they acquire in associative networks. As a result, activating one concept in the network may automatically activate the rest of the network. Since people's representation of time is closely associated with happiness (Carstensen, Isaacowitz, \& Charles 1999; Van Boven \& Gilovich 2003) while that of money is closely associated with economic utility (Lowenstein, Reid, \& Baumeister 2003), Liu \& Aaker (2008) argue that asking people to consider giving time activates well-being goals while considering giving money suppresses such goals and activates instead goals of economic utility (Brendl, Markman, and Messner 2003). In support of their claim, Liu \& Aaker (2008) found that first asking participants about their mere intention to donate time (money) in favor of a charity before asking them to actually donate money to that charity significantly increased (decreased) the amount donated. Process insights suggested that this effect was in effect due to different mindsets. Merely considering 
to donate time led participants to an emotional mindset in which giving was seen as a means toward emotional well-being and happiness. Thinking about donating money, in contrast, led participants to a value-maximizing mindset wherein the role of giving was seen less positively. In sum, measuring intentions to give time led to a more positive inclination to give, whereas measuring intentions to donate money led to more disengagement from giving.

While the evidence provided in these studies supports the argument developed, such an account would not explain why some consumers may prefer donating money while others prefer donating time when the two options are presented simultaneously. Indeed, since volunteering time seems to be more closely associated with happiness than donating money (Liu \& Aaker 2008), one would expect consumers to systematically prefer donating time, provided that the costs of donating time and money are equated (e.g., 5 hours vs. \$100). Since such a systematic pattern may not fully describe consumer preference heterogeneity, what alternative mechanisms could explain why some consumers prefer donating time while others favor donating money?

Research by Reed et al. (2007b) may provide an initial response to this question. Extending social resource theory (Foa \& Foa 1980), Reed et al. (2007b) argue that one's orientation between donating time and money may be partly determined by the importance of one's moral identity, i.e., one's conception of how moral one is. Indeed, while donating money is generally a more rapid, indirect, and passive way of providing a social benefit, giving time requires a greater psychic and behavioral investment. Because donating time requires greater investment of the self, consumers who construe themselves as highly moral individuals will favor volunteerism (over financial philanthropy), as it more powerfully reinforces their moral self. 
We extend the above stream of research on personality and moral identity by looking at the influence that situational factors may have on charitableness and donor orientation. Referring to self-affirmation theory (Steele \& Liu 1983, Steele 1988, Steele, Spencer, \& Lynch 1993), we propose that ego-threats, i.e., instances where one's self-view is momentarily called into question by external agents or events, can help foster charitable behavior and lead individuals to prefer donating time over money to their favorite charities. Furthermore, we hypothesize that this state of preference for time contributions when the self is under threat derives from perceiving volunteerism as more repairing than financial philanthropy. Indeed, to the extent that volunteering is likely to entail social exchange, the prospect of spending time with others may help mitigate ego-threats by creating meaning in life and establishing feelings of social embeddedness (Carstensen 1995, Rothbart 1994).

We start our investigation by testing the prediction that ego-threats can lead charitably-oriented consumers to volunteer time more readily than money (study 1 ). In study 2, we examine an alternative explanation for study 1's findings and show that, far from activating money-protection goals, ego-threats can actually lead consumers to donate more money to their favorite charity. In study 3, we test the hypothesis that ego-threatened participants may favor volunteerism over financial philanthropy because the former seems more repairing than the latter. In study 4, we shift our focus to the nature of ego-threats and show that a given threatening event may impact consumer donation behavior differently. We conclude by discussing the implications of our findings for theory and practice.

\section{Study 1}

The purpose of study 1 was to test the hypothesis that, when threatened, the self becomes more likely to exhibit charitableness by volunteering time than by donating money. 
To induce threat, we adopted a procedure by Brinol \& Petty (2003) and Gao, Wheeler, \& Shiv (2007). Participants first engaged in a graphology experiment whose alleged purpose was to predict their potential as a student and later as a business professional. Next, participants completed a seemingly unrelated volunteerism study. In line with our conceptualization, we predicted that participants in the threat condition during the graphology study would become more likely than control participants to favor volunteerism over financial philanthropy.

Participants and procedure. A total of forty six undergraduate students from a large southeastern American university took part in study 1 . Thirty five students from the business school participated in exchange for course credit while the remaining eleven were recruited on campus and compensated $\$ 5$ for completing short surveys in a 30 minutes long research session. Sessions were run in small groups of about twelve individuals.

Upon arrival to our laboratory, participants were greeted and given time to read and sign a consent form. Next, they were told that the first study they would complete was a graphology experiment (cf. appendix 1) whose aim was to assess their potential as a student and later as a business professional. Instructions asked all participants to write a 100-word essay (+ or $-10 \%)$ in which they would develop three arguments illustrating why they are intelligent. Instructions in the threat condition differed from the control only in asking participants to use their nondominant hand (i.e., their left hand if they were right-handed, or their right hand if they were left-handed) to write the essay. Such a manipulation has been shown to reduce confidence in the arguments being developed and ultimately in the self (Brinol \& Petty 2003). Following this handwriting manipulation, we collected demographics 
(e.g., age, gender, GPA) and administered a seemingly unrelated survey about volunteerism (cf. appendix 2).

Dependent variables. The volunteerism survey indicated that the intent of the study was to capture people's true feelings and attitudes about volunteerism. After assuring participants that there were no right or wrong answers to the questionnaire and that we were only interested in their genuine responses (cf. Olson, Fazio, \& Hermann 2007), we asked participants to indicate what they would be more likely to do in behalf of their favorite charity between donating a certain sum of money (i.e., $\$ 10, \$ 30, \$ 50, \$ 70, \$ 90, \$ 110, \$ 130$ ) and volunteering a day of work. Seven questions were asked, each of which was anchored by a monetary donation (e.g., \$10) on one end of the scale vs. volunteerism (i.e., one day’s worth of work) on the other. An eighth question concluded the survey by asking participants what they would rather do in general between "donating money" and "volunteering time" for their favorite charity. All answers were reported on 1 to 8 likert scales such that no indecisive midpoint was available.

\section{Results}

Manipulation check. To validate our procedure, we pretested our manipulation in a sample of students from the same southeastern American university. Upon completion of the handwriting task described earlier, we asked participants to indicate on a 1 (not at all) to 7 (very) scale how confident they were in the arguments developed in their essay and the extent to which they felt intelligent at this very moment. As expected, we found that participants in the threat condition felt both less confident $\left(\mathrm{M}_{\text {threat }}=4.0 \mathrm{vs} . \mathrm{M}_{\text {control }}=5.1 ; \mathrm{F}\right.$ $(1,43)=6.8, \mathrm{p}<.02)$ and less intelligent $\left(\mathrm{M}_{\text {threat }}=4.6\right.$ vs. $\mathrm{M}_{\text {control }}=5.3 ; \mathrm{F}(1,43)=4.9, \mathrm{p}<$ .04) than control participants. Yet, when asked about the importance of intelligence to their 
self-esteem, both groups expressed that intelligence was highly important $\left(\mathrm{M}_{\text {threat }}=6.1 \mathrm{vs}\right.$. $\left.\mathrm{M}_{\text {control }}=5.9 ; \mathrm{F}(1,43)<1, \mathrm{NS}\right)$. Such high means on a 7-point scale suggest that our threat manipulation did strike a key aspect of our participants' ego.

Dependent variables. An analysis of variance on our dependent variables confirmed our hypothesis: Threatened participants were generally more likely to donate time over money than control participants. On the first dependent measure (i.e., donating $\$ 10$ vs. volunteering one day of work), control participants reported being more likely to donate money while threatened participants reported being more likely to donate time $\left(\mathrm{M}_{\text {control }}=3.8\right.$ vs. $\left.\mathrm{M}_{\text {threat }}=5.7 ; \mathrm{F}(1,44)=8.0, \mathrm{p}<.01\right)$. This pattern held on the second dependent measure (i.e., donating $\$ 30$ vs. volunteering one day of work) whereby subjects in the threat condition were more likely to volunteer time than their counterparts in the control condition $\left(\mathrm{M}_{\text {control }}=\right.$ 5.4 vs. $\left.\mathrm{M}_{\text {threat }}=6.6 \mathrm{~F}(1,44)=5.7, \mathrm{p}<.03\right)$. The third measure (i.e., donating $\$ 50$ vs. volunteering one day of work) marginally replicated this pattern of results $\left(\mathrm{M}_{\text {control }}=6.2 \mathrm{vs}\right.$. $\left.\mathrm{M}_{\text {threat }}=7.0 \mathrm{~F}(1,44)=2.8, \mathrm{p}=.1\right)$. The next four measures (i.e., donating $\$ 70, \$ 90, \$ 110$, $\$ 130$ vs. volunteering one day of work) did not reach conventional levels of statistical significance (Fs $<1, \mathrm{NS})$. The eighth and last measure, which captured what participants would rather do in general between contributing money and time, confirmed the previous findings $\left(\mathrm{M}_{\text {control }}=5.2\right.$ vs. $\left.\mathrm{M}_{\text {threat }}=6.7 ; \mathrm{F}(1,44)=5.7, \mathrm{p}<.03\right)$.

\section{Discussion}

These results seem to support our hypothesis: When their self-confidence was shaken, participants became more likely to volunteer time than donate money to their favorite charity. Yet, we see that this effect was bounded by the monetary donation requested. As the dollar amount increased, participants gradually preferred donating time over money. Past a certain 
threshold, both control and threatened participants so overwhelmingly preferred volunteering time that differences between the two groups became statistically undistinguishable. Expectedly, limited financial resources on the part of our students left them with only volunteerism as a viable option once the monetary donation requested passed the $\$ 50$ mark.

We have so far argued that a momentary state of ego-threat can foster charitable behavior, particularly in the form of volunteerism. Though study 1's findings seem supportive of this claim, one challenging argument must be considered. What if this preference for volunteerism were not genuine but constrained by the binary nature of our dependent variables? It is conceivable after all that, rather than making participants more positively generous with their time, ego-threats activate instead a money-protection goal. If so, our participants might not have become more genuinely charitable in the form of time contributions; rather, they may have felt constrained to be so in order to save money. In the next study, we adjust our experimental paradigm to ascertain which of these two explanations can best account for participants' preferences in study 1 .

\section{Study 2}

Study 1 left open for debate the interpretation of its results. While we had hoped to show that ego-threats may indeed strengthen consumers' preference for volunteerism over financial philanthropy, an alternative interpretation of our results emerged. According to this latter account, rather than fostering genuine charitableness in the form of time contributions, ego-threats may have activated instead a money-protection goal, which in turn led participants to donate time in an effort to save money. The goal of study 2 was to tease apart which of these two interpretations best fits the effect witnessed in study 1. To induce threat, we again adopted Brinol \& Petty's procedure (2003; cf. study 1). Next, participants 
completed a short and seemingly unrelated donation survey where they indicated which organization constituted their favorite charity as well as how much money, if any, they wished to contribute to it. Of importance here are the differences in predictions made. Consistent with our theorizing, we predicted that, in an attempt to repair their bruised selfesteem, participants in the threat condition would donate more money than control participants. In contrast, the alternative explanation outlined earlier would predict the opposite, namely that threatened participants would pursue a money-protection goal and therefore donate less to their favorite charity.

Participants and procedure. A total of 68 undergraduate students from a large southeastern American university were recruited on campus and compensated $\$ 5$ for completing short surveys in a 30 minutes long research session. Sessions were run in small groups of about twelve individuals. The procedure followed that of study 1 with one exception: Upon completion of the graphology study, participants moved on to a short donation survey in which they described their favorite charity and indicated how much money, if any, they wished to contribute to it. The amount of money pledged by each participant constituted our dependent variable.

Results. As expected, an analysis of variance with age and gender serving as covariates revealed that participants in the threat condition donated marginally more than control participants $\left(\mathrm{M}_{\text {threat }}=\$ 2.59\right.$ vs. $\left.\mathrm{M}_{\text {control }}=\$ 1.64 ; \mathrm{F}(1,64)=3.6, \mathrm{p}<.07\right)$.

\section{Discussion}

Two radically different interpretations could make sense of study 1's findings. While we wished to argue that a state of self-threat led charitably-oriented consumers to genuinely favor volunteerism over financial philanthropy, we had to consider an alternative account: 
Rather than fostering a positive preference for donating time, it is possible that our manipulation activated instead a money protection goal. As a result, threatened subjects were constrained by the nature of our dependent variable to donate time in order to save money. To ascertain which of these two interpretations could best explain our participants' preferences, in study 2 we used a monetary dependent variable. In a donation survey, students described their favorite charity and indicated how much money they wished to contribute to it. We predicted that participants in the threat condition would exhibit more generosity (i.e., donate more) as a way to repair their bruised esteem. In contrast, the competing account predicted that threatened participants would exhibit less generosity (i.e., donate less) in an effort to protect their finances. In line with our theorizing, we found that threatened participants donated $63 \%$ more of their own money than control participants. Hence, consistent with our hypothesis, ego-threats seem to have indeed the potential to foster, not hinder, charitableness. In fact, consistent with self-affirmation theory (Steele \& Liu 1983, Steele 1988, Steele, Spencer, \& Lynch 1993), it is conceivable that consumers may use charitable behavior strategically, though not necessarily consciously, as a means to repair their bruised self-esteem.

But what would explain why threatened consumers favor donating time rather than an equivalent amount of money, as suggested by study 1 ? As mentioned earlier, we believe that volunteering may provide greater repair potential to the injured self than donating money. Indeed, to the extent that volunteering is likely to entail social exchange, the prospect of spending time with others may help regulate emotional states by creating meaning in life and establishing feelings of social embeddedness (Carstensen 1995, Rothbart 1994). In contrast, thinking about money tends to elicit more individualistic and self-sufficient goals 
(Loewenstein, Read, \& Baumeister 2003; Vohs, Mead, \& Goode 2006). Together, these forces combine to lend support to our claim that when given the opportunity to choose, egobruised consumers might find in volunteerism a better venue to restore their self-worth. We set out to test this hypothesis in the next study.

\section{Study 3}

The goal of study 3 was to shed light on why charitably-oriented consumers may favor volunteerism over financial philanthropy when under threat. To this end, we created a word integration task (WIT) for which participants completed a series of word problems before receiving bogus performance feedback. Next, borrowing a task from the selfaffirmation literature, we gave some participants the opportunity to repair their bruised selfesteem in a seemingly unrelated memory study. Participants then went on to complete a shortened version of our volunteerism survey (cf. study 1). To conclude, participants filled out an attitude questionnaire whose alleged purpose was to capture consumers' attitudes about charitable donations. In reality, the attitude questionnaire was intended to capture participants' motives for choosing to donate time vs. money in the previously completed volunteerism survey.

Participants and procedure. One hundred and one undergraduate students from a large southeastern American university were recruited on campus and paid $\$ 5$ for participating in a 30 minutes long research session in which study 3 was included. Sessions were run in groups of about fifteen individuals.

As they arrived to the laboratory, participants were greeted and given time to read a consent form. After signing the form, participants received a stack of surveys, which included the word integration task. On its cover page, the WIT (cf. appendix 3) displayed 
instructions in two parts. Part 1 informed participants that their goal in the study would be to generate words, which, given a set of three clue words, would result in word pairs that form a common compound word or phrase. Three examples were then given as illustrations.

Example 1 read "cottage/swiss/cake" and offered the solution "cheese, as in cottage cheese, Swiss cheese, and cheese cake." The second part of instructions informed participants that they would find on the next page twelve similar word problems and that they would be given six minutes to complete as many of them as possible. After verifying that everyone had had enough time to review the examples, the experimenter instructed participants to turn the page and start the study. Six minutes later, participants were informed that time was up and instructed to turn the page. On the following page, participants discovered an answer key and a bogus performance table. Participants in the control (threat) condition read that 0 or 1 ( 8 or fewer) correct answers placed them in the bottom third; 2 or 3 (9 or 10) correct answers placed them in the middle third; and finally, that 4 or more (11 or 12) correct answers placed them in the top third of performers. In reality, to make up the WIT, we selected twelve remote associates problems of average difficulty from Bowden \& Beeman (2003), i.e., problems pretested such that participants would solve $50 \%$ of them within 30 seconds. Hence, we expected participants to solve on average six problems, thereby leading them to believe that they belonged to the top third of performers if they were in the control, or bottom third if they were in the threat condition.

Underneath the answer key and performance table, a stem written in the first person (i.e., I had__ correct answers) prompted participants to report the number of correct answers they were able to generate. Next, instructions asked participants to refer to the performance table and indicate which performance group they belonged to, based on the 
number of correct answers they had. To report their performance, participants were to check the appropriate space in the stem "My performance places me in the _ top third; __ middle third; _ bottom third." The last question on the page asked participants to indicate how difficult they found the word integration task on a 1 (not at all) to 7 (extremely) likert scale. The following page consisted of Heatherton \& Polivy's (1991) performance-related selfesteem subscale (cf. appendix 4).

Upon completion of the WIT, participants discovered the memory study whose alleged purpose was to examine how well people can remember mundane events of life. In reality, we borrowed a repair procedure from the self-affirmation literature (Steele 1988; White \& Lehman 2005; cf. appendices 5 and 6) to provide some participants an opportunity to restore their bruised self-esteem. After ranking the importance of eleven traits and values (e.g., relations with friends, sense of humor, social skills), participants in the self-affirmation (no self-affirmation) condition were asked to explain why their first (ninth) ranked value was important to them (may be important to someone else) and to recall in detail one instance where expressing or acting on this value had caused them (someone other than them) to feel good about themselves. Next, participants completed Robins, Hendin, \& Trzesniewski's (2001) measure of state self-esteem (cf. appendix 7) and a shorter version of the volunteerism survey (cf. study 1). Only the first three donation questions of the original survey were featured here (i.e., donating $\$ 10, \$ 30, \$ 50$ vs. volunteering one day of work).

Finally, participants filled out an attitude questionnaire whose alleged purpose was to capture consumers' attitudes about charitable donations. In reality, the purpose of this questionnaire was to gain insights about participants' motivation for choosing to donate time vs. money in the previously completed volunteerism survey. In line with our 
conceptualization, we devised a short scale to assess participants' beliefs about the repair efficacy of time vs. money donations. To validate the measure, 189 pretest participants indicated on a 1 (not at all) to 7 (very much) likert scale the extent to which they agreed or disagreed with a series of statements. All statements in the scale followed the stem "It is more to support a charitable cause by donating time rather than money", where the adjectives "enriching, fulfilling, rewarding, satisfying, uplifting" were successively inserted in place of the blank. A varimax rotated factor analysis confirmed that all five items loaded on only one factor (cf. table 1). We thus collapsed these items into one aggregate measure $(\alpha=.87)$ such that higher (lower) scores indicated stronger beliefs that volunteerism (financial philanthropy) is indeed more repairing than financial philanthropy (volunteerism).

\section{Results}

As mentioned earlier, to devise the WIT, we selected twelve word problems of average difficulty from Bowden \& Beeman (2003), i.e., problems pretested such that participants would solve $50 \%$ of them (i.e., 6 problems) within 30 seconds. Most control (threatened) participants conformed to these expectations and therefore wound up believing that they belonged to the top (bottom) third of performers. Twenty five participants, however, solved either far fewer or far more problems than expected and wound up believing that they belonged to the middle third of performers. These participants were withdrawn from our analyses so as to not bias our results.

Manipulation checks. To validate our experimental procedure, we submitted the data collected in the word integration task and the first self-esteem scale (Heatherton \& Polivy 1991) to an analysis of variance. As expected, our Anova confirmed that participants assigned to the threat condition, i.e., participants whose performance feedback led them to 
believe that they belonged to the bottom third of performers, perceived the WIT to be more difficult than participants in the control condition, i.e., participants led to believe they belonged to the top third of performers $\left(\mathrm{M}_{\text {threat }}=4.9\right.$ vs. $\mathrm{M}_{\text {control }}=4.4 ; \mathrm{F}(1,69)=5.0, \mathrm{p}<$ .03). Perhaps more importantly, our Anova further revealed that threatened participants exhibited less favorable levels of self-esteem $\left(\mathrm{M}_{\text {threat }}=26.6 \mathrm{vs} . \mathrm{M}_{\text {control }}=30.0 ; \mathrm{F}(1,69)=\right.$ $13.1, \mathrm{p}<.01)$. To look at the effect of our repair manipulation, we examined participants' state of self-esteem immediately after the self-affirmation procedure (i.e., the memory study). Our Anova on this 2 (Control vs. Threat) by 2 (Self-affirmation vs. No self-affirmation) between-subjects design revealed no main effects (Fs < 1) but a marginally significant interaction $(\mathrm{F}(1,69)=3.1, \mathrm{p}<.09)$. As expected, in the control condition, having an opportunity to self-affirm seemed to have no impact on self-esteem $\left(\mathrm{M}_{\text {no self-affirmation }}=4.1 \mathrm{vs}\right.$. $\mathrm{M}_{\text {self-affirmation }}=3.8$ ). In the threat condition, however, participants who didn't get to selfaffirm exhibited esteem levels inferior to that of their counterparts in the affirmation condition $\left(\mathrm{M}_{\text {no self-affirmation }}=3.5\right.$ vs. $\mathrm{M}_{\text {self-affirmation }}=4.0$; cf. figure 1). Collectively, these results suggest that our manipulations functioned as intended.

Dependent variables. Having verified that our manipulations had produced their intended effect, we next turned our attention to the dependent variables. An analysis of variance on the first outcome measure (i.e., donating $\$ 10$ vs. volunteering one day of work) revealed no main effects $(\mathrm{Fs}<1)$ but a significant interaction $(\mathrm{F}(1,69)=4.5, \mathrm{p}<.04$; cf. figure 2). In the control condition, having an opportunity to self-affirm seemed to have no impact on participants' charitable orientation $\left(\mathrm{M}_{\text {no self-affirmation }}=4.8 \mathrm{vs} . \mathrm{M}_{\text {self-affirmation }}=5.5\right)$. In the threat condition, however, participants who had not had an opportunity to reaffirm their self-worth exhibited stronger preferences for donating time over money than their 
counterparts in the self-affirmation condition $\left(M_{\text {no self-affirmation }}=6.2 \mathrm{vs} . \mathrm{M}_{\text {self-affirmation }}=4.9\right)$. This pattern of results carried over to the next outcome measure (i.e., donating \$30 vs. volunteering one day of work) at a marginal level of statistical significance $(F(1,69)=2.9, p$ $<.1$ ) but failed to do so for the last dependent variable (donating $\$ 50$ vs. volunteering one day of work; $F(1,69)<1.1, \mathrm{NS})$.

Mediation analysis. To explain why ego-threats may lead consumers to favor volunteerism over financial philanthropy, we proposed that the repair efficacy of the former may be perceived to be greater than that of the latter. To examine this hypothesis, we tested whether participants' answers to the attitude questionnaire mediated their preference for time vs. money contributions. Our dependent variable in the present analysis is participants' answer to the first question of the volunteerism survey (i.e., donating \$10 vs. volunteering one day of work).

According to Baron \& Kenny (1986), mediation is supported if: (1) the independent variable predicts the outcome variable; (2) the independent variable predicts the supposed mediator; and (3) the mediator predicts the outcome variable in the presence of the independent variable. In the case of a mediated moderation, the same requirements apply but the independent variable becomes the interaction term and its constituting main effects are treated as covariates.

As mentioned earlier, an Anova on our dependent variable revealed no main effects $(\mathrm{Fs}<1)$ but a significant threat by affirmation interaction $\mathrm{F}(1,69)=4.5, \mathrm{p}<.04)$. We replicated these results in a regression analysis $\left(\mathrm{B}_{\text {threat }}=.209, \mathrm{t}<1, \mathrm{NS} ; \mathrm{B}_{\text {affirmation }}=-.164, \mathrm{t}<\right.$ $\left.1, \mathrm{NS} ; \mathrm{B}_{\text {threat by affirmation }}=-.475, \mathrm{t}=2.1, \mathrm{p}<.04\right)$, thereby satisfying Baron \& Kenny's $(1986)$ first condition. Next, using participants' scores on the attitude questionnaire as the outcome 
variable, we ran a second regression analysis and found again no main effects but a marginally significant threat by affirmation interaction $\left(\mathrm{B}_{\text {threat }}=-.033, \mathrm{t}<1, \mathrm{NS}\right.$; $\mathrm{B}_{\text {affirmation }}=-$ $.777, \mathrm{t}<1.2, \mathrm{NS} ; \mathrm{B}_{\text {threat by affirmation }}=-1.264, \mathrm{t}=1.9, \mathrm{p}=.06$ ). These results suggest that our interaction term could also predict the mediator, thereby satisfying condition 2. Lastly, to test condition 3, we ran a regression analysis which included as predictors our two main effects, their interaction term, and the mediator. In this last model, only the mediator remained a significant predictor of the dependent variable $\left(\mathrm{B}_{\text {threat }}=.213, \mathrm{t}=1.0, \mathrm{NS} ; \mathrm{B}_{\text {affirmation }}=-.068, \mathrm{t}\right.$ $\left.<1, \mathrm{NS} ; \mathrm{B}_{\text {threat by affirmation }}=-.318, \mathrm{t}=1.5, \mathrm{NS} ; \mathrm{B}_{\text {mediator }}=.124, \mathrm{t}=3.2, \mathrm{p}<.01\right)$, thereby suggesting mediation. A marginally significant Soble test (1982) confirmed this effect ( $\mathrm{z}=$ $1.6, \mathrm{p}<.1)$.

\section{Discussion}

The goal of study 3 was to further investigate the link between ego-threats and charitable behavior. More specifically, we sought to examine why charitably-oriented consumers may favor volunteerism over financial philanthropy after facing ego-threatening situations. To induce threat, we provided participants poor performance feedback upon completion of a problem-solving task. Next, we gave some participants an opportunity to restore their sense of self-worth by affirming values important to them in a writing task (Steele 1988; White \& Lehman 2005). As in study 1, we found that participants expressed stronger preferences for donating time over money when under threat. Yet, this effect weakened when subjects had an opportunity to reaffirm their self. To explain why ego-threats lead consumers to exhibit charitableness more readily through time than money donations, we proposed that the repair potential of the former may be perceived to be greater than that 
of the latter. In line with this argument, we found that participants' beliefs about the repair efficacy of volunteerism mediated the effect of threat on donation behavior.

While study 3 shed light on why charitably-oriented consumers may favor volunteerism over financial philanthropy, our investigation has yielded few insights so far about the nature of the threats at work. In studies 1 and 2, our ego-threats pertained to one's perception of one's intelligence. In study 3, our threat manipulation consisted of failure feedback on a problem-solving task. Though different in some regards, these tasks could also be seen as variations on the same theme: intellectual achievement. Hence, one might wonder about the generalizability of our findings. Do all threats lead to favor volunteerism over financial philanthropy? Or are our results the byproducts of the specific manipulations we used? In the next study, we set out to examine the extent to which the nature of the threat at play may influence donation behavior. Specifically, we examine whether the basic effect found in studies 1 and 3 can be moderated by the centrality of the threat to one's selfconcept.

\section{Study 4}

The purpose of study 4 was to further test the relationship between ego-threats and charitableness. Specifically, we sought to examine whether the centrality of the threat to one's self-concept may moderate the general impact of ego-threats on donation behavior. To induce threat, we created a task requiring that participants compare themselves to pictures of attractive young men and women. Next, participants completed a seemingly unrelated volunteerism survey. In line with our conceptualization, we expected that participants in the threat condition during the picture study would become more likely than control participants to volunteer time over money. Yet, we qualified this prediction by restricting it to 
participants whose self-esteem significantly depends on physical appearance. In other words, we expected that our threat manipulation would produce its greatest effect on participants for whom personal attractiveness matters most.

Participants and procedure. A total of fifty three undergraduate students from the same large southeastern American university took part in study 4. Thirty six students from the business school participated in exchange for course credit while the remaining seventeen were recruited on campus and compensated $\$ 5$ for completing short surveys in a 30-minute research session. Sessions were run in small groups of about twelve individuals.

Upon arrival to our laboratory, participants were greeted and given time to read and sign a consent form. Next, participants were handed the picture study, our threat manipulation. Instructions on the cover page informed participants that we had selected pictures of college students from a popular website. Participants were to review this assortment of anonymous photographs and indicate for each picture how attractive the person was compared to them (cf. appendices 8 and 9). Instructions further stressed "Please try to be as accurate as possible. Using a "third person" approach may help. For instance, if someone other than you were to judge your attractiveness vs. that of the person depicted, what would they say?" The next few pages presented five photographs. Each photo was followed by the stem "Compared to this person, I am..." and a 1 (not at all attractive) to 9 (very attractive) likert scale on which participants reported their rating. When finished with the picture study, participants filled out the Positive Affect Negative Affect Schedule (PANAS) scale (Watson, Clark, \& Tellegen 1988; cf. appendix 10) whose purpose was to serve as a manipulation check, and a shortened version of the volunteerism survey (cf. study 1). After filling out several unrelated questionnaires, participants ended the research session 
by completing Crocker et al.’s Contingencies of Self-Worth scale (2003; cf. appendix 11).

Our goal here was to capture how important each participant's physical appearance was to his/her self-esteem.

Threat manipulation. To create the picture study, we selected twenty photographs from the popular website amihotornot.com, where thousands of people post pictures of themselves for visitors of the site to rate. The pictures we presented in the control condition consisted of five young men (women, if the participant was female) of average attractiveness, whereas those featured in the threat condition consisted of five young and highly attractive men (women). Our goal here was to threaten participants' ego by engaging them in selfcomparisons with attractive individuals of their sex.

\section{Results}

Manipulation checks. As expected, across all five pictures, participants in the threat condition evaluated themselves less favorably than their counterparts in the control condition $\left(\mathrm{M}_{\text {threat }}=5.8\right.$ vs. $\left.\mathrm{M}_{\text {control }}=7.2 ; \mathrm{F}(1,52)=12.3, \mathrm{p}<.01\right)$. Analyses of the PANAS data also revealed that threatened participants experienced less positive affect $\left(\mathrm{M}_{\text {threat }}=23.1 \mathrm{vs} . \mathrm{M}_{\text {control }}\right.$ $=30.6 ; \mathrm{F}(1,52)=15.1, \mathrm{p}<.01)$ and marginally more negative affect $\left(\mathrm{M}_{\text {threat }}=14.6 \mathrm{vs}\right.$. $\left.\mathrm{M}_{\text {control }}=12.5, \mathrm{~F}(1,52)=3.2, \mathrm{p}<.09\right)$. Collectively, these findings suggest that our threat manipulation did function as intended.

Dependent variable. The dependent variable in this shortened version of the volunteerism survey consisted of the last question of the original survey, i.e., In general, what would you rather do between donating money and volunteering time in favor of your preferred charity? With age and gender as covariates, an analysis of variance on this 2 (Control vs. Threat) by 2 (Importance of physical appearance: Low vs. High) design revealed 
no main effects $(\mathrm{Fs}<1)$ but a significant interaction $(\mathrm{F}(1,47)=4.3, \mathrm{p}<.05$; cf. figure 3$)$. In the control condition, participants caring less about their appearance did not differ from those caring more in terms of preferring to donate time over money $\left(\mathrm{M}_{\text {low appearance importance }}=5.3 \mathrm{vs}\right.$. $\mathrm{M}_{\text {high appearance importance }}=4.8$ ). In the threat condition, however, while participants low on appearance importance remained indifferent between donating time and money, those high on appearance importance increasingly favored donating time $\left(\mathrm{M}_{\text {low appearance importance }}=4.7 \mathrm{vs}\right.$. $\mathrm{M}_{\text {high appearance importance }}=5.9$ ).

\section{Discussion}

The results of study 4 replicate our previous findings and further confirm our hypothesis that, when threatened, the self may prefer to exhibit charitableness through time rather than monetary donations. Furthermore, study 4 extends our previous findings by shedding light on the importance of the threat's nature. Indeed, our results here suggest that a given threatening event may impact consumers differently. In the present case, while engaging in threatening comparisons strengthened preferences to volunteer time for individuals heavily invested in their looks, it didn't do so for individuals less concerned by their physical appearance. As alluded to earlier, we believe that participants low on appearance importance did not exhibit a behavioral shift in favor of volunteerism because the threat did not concern a core aspect of their self.

\section{General discussion}

On any given day, consumers face a multitude of situations with the potential to damage their sense of self and identity (Sherman \& Cohen 2006; Steele 1988). Examples of such situations include disappointing a significant other, underperforming on the job, failing to deliver on a promise, gaining weight, etc. The purpose of this research was to examine 
how ego-threats, i.e., instances where one's self-view is momentarily called into question by external agents or events, can influence charitable behavior. Two propositions guided our enquiry. First, we hypothesized that a state of self-threat may have the potential to foster charitableness in consumers. Grounding this prediction in self-affirmation theory, (Steele \& Liu 1983, Steele 1988), we proposed that by affirming a generous and/or compassionate dimension of the self, volunteerism, and to some extent financial philanthropy, may serve a repair function for the injured self. Furthermore, we hypothesized that if given the choice, ego-threatened individuals would favor to donate time rather than money. Grounding this prediction in the social psychological literature (Carstensen 1995, Rothbart 1994), we proposed that this state of preference for time contributions would derive from perceiving volunteerism as more repairing than financial philanthropy.

In line with our theorizing, we found in studies 1 and 2 that reducing one's confidence in his or her intelligence via a seemingly innocuous handwriting manipulation (Brinol \& Petty 2003) led participants to exhibit greater charitableness (i.e., donate more money) in favor of their preferred charity. Yet, when participants were given the choice to donate time or money, volunteerism became the preferred option. To examine why consumers may opt to donate time more readily than money when under threat, we provided participants in study 3 poor performance feedback upon completion of a problem-solving task. Next, we gave some participants an opportunity to restore their sense of self-worth by affirming values important to them in a writing task (Steele 1988; White \& Lehman 2005). We found again that participants expressed stronger preferences for donating time over money when under threat. Yet, this effect weakened when subjects had had an opportunity to reaffirm their self. A mediation analysis revealed that participants' beliefs about the repair 
efficacy of volunteerism mediated the effect of threat on donation behavior. In study 4, we sought to extend our findings by investigating the effect of threats unrelated to intellectual achievement. Furthermore, we sought to examine whether the centrality of the threat to one's self-concept may moderate the general impact of ego-threats on charitableness. To this end, we created a task requiring that participants compare themselves to pictures of attractive individuals of their sex before responding to a seemingly unrelated charity appeal. As expected, we found that participants in the threat condition during the picture study became more likely than control participants to volunteer time over money. Yet, this effect was restricted to participants whose self-esteem significantly depends on physical appearance (i.e., individuals heavily invested in their looks). In sum, across four experiments, we showed that ego-threatening events can indeed lead consumers to greater charitableness.

Furthermore, we found that when given the opportunity to choose, ego-bruised consumers tend to favor volunteerism over financial philanthropy as the former is perceived to be more repairing than the latter.

\section{Theoretical and managerial implications}

By demonstrating the effect that ego-threats can have on consumers' preferences to volunteer time versus money, this research contributes notably to the decision-making literature. Indeed, while prior work investigated time and money as they relate to the valuation of delayed consumption (Lowenstein 1987), slack perception (Zauberman \& Lynch 2005), or time worth (DeVoe \& Pfeffer 2007), this research highlights the psychological repair properties that time and money can offer to the self while under attack. More importantly, by highlighting some of the motivation leading consumers to exhibit charitableness, our findings also contribute to the altruism literature. Prior research has 
proposed a variety of factors to explain helping behavior. Emotions such as empathy (Batson 1987) and sympathy (Small, Lowenstein, \& Slovic 2007) have, for instance, been put forth as determinants of charitableness. Collectivism (Tajfel 1981) and mortality salience (Ferraro, Shiv, \& Bettman 2005; Jonas et al. 2002) are other known triggers. As mentioned earlier, work by Liu \& Aaker (2008) on decisional mindset and Reed et al. (2007a; 2007b) on moral identity uncovered how behavioral intentions and personality traits could also influence altruistic behavior. By shedding light on the functions that giving time or money may hold for the self at certain times, this research contributes new insights to the situational determinants of altruism.

Our findings are also informative from a managerial standpoint. Indeed, in times of economic recession (Willis \& Chandra 2008) and rarefaction of volunteers (US Labor Department 2007), harvesting help from donors constitutes the most critical challenge nonprofits face today (West 2004). By documenting the directional impact that self-threats exert on donor response, this research offers a more nuanced understanding of donor psychology. Specifically, our results may help charities design more efficient communication campaigns toward and/or retention programs of their benefactors. For instance, while little insight on the effect of ego-threats (e.g. ads featuring guilt-appeals or social comparisons) existed to guide nonprofits in their advertising strategy, the findings presented here suggest that such techniques may be advantageous in some cases (e.g., when the goal of the campaign is to draw volunteer labor) and suboptimal in others (e.g., when the objective is to raise funds while both time and money contributions are accepted).

Limitations \& future research 
While our findings support our overall theorizing, certain limitations must be noted. First among these limitations is the influence of mood in our studies. A main claim of our research is that ego-threats, i.e., instances where one's self-view is momentarily being challenged, can depress one's state of self-esteem. Referring to self-affirmation theory (Steele \& Liu 1983, Steele 1988), we further argued that by exhibiting charitableness in response to self-threats, consumers are able to affirm a generous and/or compassionate dimension of their identity. As such, engaging in volunteerism or financial philanthropy provides a repair opportunity to the injured self by, for instance, fulfilling a religious duty or adhering to a socially-praised custom. Yet, one might argue that mood, not self-esteem, may be the driving force behind our findings (Cialdini et al. 1987). Indeed, one can easily see that the type of ego-threat manipulations we use may very well also impact mood. We readily concur with this idea that mood may have been present in our studies. In fact, we even documented through our manipulation checks in study 4 that participants who had engaged in self-disserving social comparisons experienced less positive affect and more negative affect relative to participants in the control condition. Yet, two elements of our investigation lead us to believe that mood cannot in and of itself account for all of our results. The first element concerns our original experiment where the affect data we collected following the graphology study revealed that our handwriting manipulation seemed to shake participants' confidence in their intelligence, not their mood. Indeed, ego-threatened participants did not differ from control on either positive affect $\left(\mathrm{M}_{\text {threat }}=21.2 \mathrm{vs.} \mathrm{M}_{\text {control }}=22.1 ; \mathrm{F}(1,33)<1\right.$, NS $)$ or negative affect $\left(M_{\text {threat }}=15.6\right.$ vs. $\left.M_{\text {control }}=15.2 ; F(1,33)<1, \mathrm{NS}\right)$.

The second element concerns the mood argument itself. If true, this alternative explanation of our results should be able to stand experimental enquiry on its own. To test it, 
we recruited thirty four undergraduate students from the same southeastern American university and ran a two-group design experiment in which we manipulated mood, but kept self-esteem constant. In the control (negative mood) condition, participants wrote a paragraph reflecting on their current feelings and attitudes as they contemplated the picture of a (badly beaten and injured) dog (cf. appendices 12 and 13). Upon finishing their essay, participants completed a series of manipulations checks aimed at measuring mood and selfesteem (Rosenberg 1965; cf. appendix 14) before concluding with the same volunteerism survey as in study 3. As expected, manipulations checks revealed that participants in the negative mood condition perceived the picture to be less pleasant $\left(\mathrm{M}_{\text {negative mood }}=2.2 \mathrm{vs}\right.$. $\left.\mathrm{M}_{\text {control }}=7.9 ; \mathrm{F}(1,32)=199.6, \mathrm{p}<.01\right)$ or entertaining $\left(\mathrm{M}_{\text {negative } \operatorname{mood}}=1.7 \mathrm{vs.} \mathrm{M}_{\text {control }}=6.1\right.$; $\mathrm{F}(1,32)=64.6, \mathrm{p}<.01)$, but more disturbing $\left(\mathrm{M}_{\text {negative } \operatorname{mood}}=7.0\right.$ vs. $\mathrm{M}_{\text {control }}=1.4 ; \mathrm{F}(1,32)=$ 123.0, $\mathrm{p}<.01)$ and distressing $\left(\mathrm{M}_{\text {negative mood }}=6.6 \mathrm{vs.} \mathrm{M}_{\text {control }}=1.5 ; \mathrm{F}(1,32)=110.9, \mathrm{p}<.01\right)$ than control participants. Furthermore, negative-mood participants reported feeling sadder $\left(\mathrm{M}_{\text {negative mood }}=7.2\right.$ vs. $\left.\mathrm{M}_{\text {control }}=3.3 ; \mathrm{F}(1,32)=59.3, \mathrm{p}<.01\right)$ and overall worse $\left(\mathrm{M}_{\text {negative mood }}\right.$ $=6.9$ vs. $\left.\mathrm{M}_{\text {control }}=3.0 ; \mathrm{F}(1,32)=57.6, \mathrm{p}<.01\right)$ than their counterparts in the control condition. Importantly, however, our measure of state self-esteem revealed no difference between the two groups $\left(\mathrm{M}_{\text {negative mood }}=8.5\right.$ vs. $\left.\mathrm{M}_{\text {control }}=7.8 ; \mathrm{F}(1,32)=2.2, \mathrm{NS}\right)$. Having verified that our manipulation had functioned as expected, we next turned our attention to the dependent variables. For memory, the mood argument would predict that participants in the negative mood condition would again favor volunteerism more readily than control participants whereas we predicted that, in the absence of ego-threat, the null hypothesis would hold. As expected, we found that the two groups differed on none of the three dependent variables. While these results certainly do not rule out mood as a contributing 
force in shaping consumers' donation behavior, they nonetheless suggest that mood cannot in and of itself produce the behavioral shifts observed across our studies.

The second limitation we wish to acknowledge concerns the higher-order mechanism for the effect we replicated in studies 1,3 , and 4 . To explain why participants exhibit stronger preferences for donating time than money when under threat, we showed in a mediation analysis that volunteerism was perceived as more repairing than financial philanthropy (cf. study 3). In a follow-up study, we attempted to go a step further and understand why donating time may appear as a better venue to restore self-worth. To this end, we recruited from the same southeastern American university 114 undergraduate students who completed our study in exchange for course credit. Upon arrival to our laboratory, participants completed some demographics before being again randomly assigned to either a threat or control condition. In the threat (control) condition, participants completed a similar word integration task (WIT; cf. appendices 15 and 16) as the one outlined in study 3. Rather than providing either positive or negative feedback upon completion of a given set of word problems, we chose here to feature ten either easy or difficult problems, which we borrowed again from Bowden \& Beeman's (2003) bank. Upon finishing the WIT, participants completed a series of manipulation checks, Heatherton \& Polivy's (1991) performance-related self-esteem subscale, and the mood short form (Peterson \& Sauber 1983; cf. appendix 17). Next participants completed one of two versions of a seemingly unrelated donation survey named The Big Brothers Big Sisters (BBBS) Survey (cf. appendices 18 and 19). In preamble, the BBBS survey informed participants that the purpose of the study was to assess a communication campaign by the BBBS foundation. After reading the alleged ad, which introduced the organization, its mission, and some of its 
accomplishments, participants were asked to imagine what they would rather contribute in favor of BBBS between money and time. In the time-neutral condition, the survey asked participants to indicate on a 1 to 8 scale their relative preference between donating $\$ 10$ (anchored on one end of the scale) vs. 8 hours collating fundraising materials and stuffing envelopes (anchored on the other end of the scale). In contrast, the time-repair condition featured the options to donate $\$ 10$ or 8 hours helping children with their homework.

To validate our procedure, we tested the perceived repair efficacies of tutoring and collating fundraising materials. Using the same list of adjectives as in study 3 , we asked participants to indicate on a 1 (not at all) to 7 (very) scale how enriching, fulfilling, rewarding, satisfying, and uplifting they would find to tutor children and collate fundraising materials for 8 hours. As expected, participants perceived tutoring children to be more repairing than collating fundraising materials $\left(\mathrm{M}_{\text {tutoring }}=6.2 \mathrm{vs} . \mathrm{M}_{\text {collating }}=2.3, \mathrm{t}=26.4, \mathrm{p}<\right.$ .01). Further manipulations checks revealed that participants in the threat condition of the WIT predicted having performed more poorly than control participants $\left(\mathrm{M}_{\text {threat }}=1.9 \mathrm{vs}\right.$. $\left.\mathrm{M}_{\text {control }}=4.2 ; \mathrm{F}(1,113)=75.2, \mathrm{p}<.01\right)$ and reported finding the task more difficult $\left(\mathrm{M}_{\text {threat }}=\right.$ 5.9 vs. $\left.\mathrm{M}_{\text {control }}=4.5 ; \mathrm{F}(1,113)=43.8, \mathrm{p}<.01\right)$. Consistent with these results, ego-threatened participants exhibited lower levels of self-esteem $\left(\mathrm{M}_{\text {threat }}=24.8\right.$ vs. $\mathrm{M}_{\text {control }}=27.8 ; \mathrm{F}(1,113)$ $=8.8, \mathrm{p}<.01)$ and less positive mood $\left(\mathrm{M}_{\text {threat }}=12.1\right.$ vs. $\mathrm{M}_{\text {control }}=14.1 ; \mathrm{F}(1,113)=5.7, \mathrm{p}<$ .02). Having verified that our manipulations had functioned as expected, we next turned our attention to the dependent variable, i.e., participants' relative preference between donating time and money.

Because consumers are subject to various time and financial constraints which may in turn impact baseline donor orientation, we attempted to control in this study for our 
participants' idiosyncratic opportunity costs of time and money. To do so, we asked respondents to indicate how much free time they had on a weekly basis as well as how much money they would be willing to pay to keep it (i.e., how much was worth this time to them). With these two elements as covariates, an Anova on this 2 (Threat vs. Control) by 2 (Time: Repair vs. Neutral) design revealed no main effects (Fs < 1.7) but a marginally significant interaction $(F(1,108)=2.8, p<.1 ;$ cf. figure 4$)$. In the control condition, participants facing the choice of donating $\$ 10$ vs. 8 hours tutoring children did not differ from those contemplating donating $\$ 10$ or 8 hours stuffing envelopes on behalf of $\mathrm{BBBS}\left(\mathrm{M}_{\mathrm{time}}\right.$ repair $=$ 3.5 vs. $\left.\mathrm{M}_{\text {time neutral }}=3.7\right)$. In the threat condition, however, participants in the time-repair condition exhibited increasingly stronger preferences for donating time (i.e., tutoring children) whereas their counterparts in the time-neutral condition increasingly favored donating money $\left(\mathrm{M}_{\text {time repair }}=4.2 \mathrm{vs} . \mathrm{M}_{\text {time neutral }}=2.8\right)$.

In sum, these results suggest that while volunteerism may seem preferable at first sight to the ego-threatened consumer, such a preference can be reversed in favor of financial philanthropy under certain conditions. Indeed, participants in the threat condition considered donating time only when time was perceived to be repairing, i.e., when it entailed tutoring children. In contrast, when donating time involved less repairing activities such as collating fundraising materials and stuffing envelopes, ego-threatened participants preferred to contribute money. Hence, we believe that future research on the mental representation of volunteerism may be instrumental in understanding why and how consumers resort to volunteer rather than donate money. We conjecture that consumers may naturally construe volunteerism at an abstract and desirable level. As a result, when facing the choice to donate time or money, it may be easier to think of volunteering in more positive or repairing terms 
than donating money. Along these lines, further research on the assumed social dimension of volunteering may also hold value. Specifically, one might examine whether volunteerism automatically evokes thoughts of direct contact with the beneficiaries of our help (as is the case in our last study) or of belongingness and togetherness, as is the case when one directly interacts with fellow volunteers (e.g., Habitat for Humanity). If so, the strength of such mental associations may in turn moderate one's orientation between donating time and money.

\section{Conclusion}

Time and money donations are inherently consumer decisions. Indeed, either one of these resources not allocated to a charitable cause could, or will, otherwise be invested in consumption-related activities (Reed et al. 2007b). The intention of this research was to show that ego-threats, i.e., menaces to one's sense of self and identity, can foster charitableness and influence donor orientation between volunteerism and financial philanthropy. The findings documented across our experiments call for further investigation of the meaning that volunteering time and donating money hold for the self. By better understanding their respective function, we shall be able to assess more accurately the value that consumers can extract from one act of charitableness versus the other. 


\section{Tables}

Table 1

Total Variance Explained and Factor Loadings (study 3)

\begin{tabular}{|c|c|c|c|c|c|c|}
\hline \multirow[b]{2}{*}{ Component } & \multicolumn{3}{|c|}{ Initial Eigenvalues } & \multicolumn{3}{|c|}{$\begin{array}{l}\text { Extraction Sums of Squared } \\
\text { Loadings }\end{array}$} \\
\hline & Total & $\begin{array}{l}\% \text { of } \\
\text { Variance }\end{array}$ & $\begin{array}{l}\text { Cumulative } \\
\%\end{array}$ & Total & $\begin{array}{l}\% \text { of } \\
\text { Variance } \\
\end{array}$ & $\begin{array}{l}\text { Cumulative } \\
\%\end{array}$ \\
\hline $\begin{array}{l}1 \\
2 \\
3 \\
4 \\
5\end{array}$ & $\begin{array}{l}3.279 \\
.599 \\
.484 \\
.376 \\
.263 \\
\end{array}$ & $\begin{array}{l}65.574 \\
11.978 \\
9.670 \\
7.521 \\
5.257 \\
\end{array}$ & $\begin{array}{l}65.574 \\
77.552 \\
87.222 \\
94.743 \\
100.000 \\
\end{array}$ & 3.279 & 65.574 & 65.574 \\
\hline $\begin{array}{l}\text { Component } \\
\text { matrix (a) }\end{array}$ & \begin{tabular}{|l} 
Component \\
1 \\
\end{tabular} & & & & & \\
\hline $\begin{array}{l}\text { Q1 } \\
\text { Q2 } \\
\text { Q3 } \\
\text { Q4 } \\
\text { Q5 }\end{array}$ & $\begin{array}{l}.841 \\
.824 \\
.887 \\
.780 \\
.705\end{array}$ & & & & & \\
\hline
\end{tabular}

Extraction Method: Principal Component Analysis.

(a) 1 components extracted. 


\section{Figures}

Figure 1

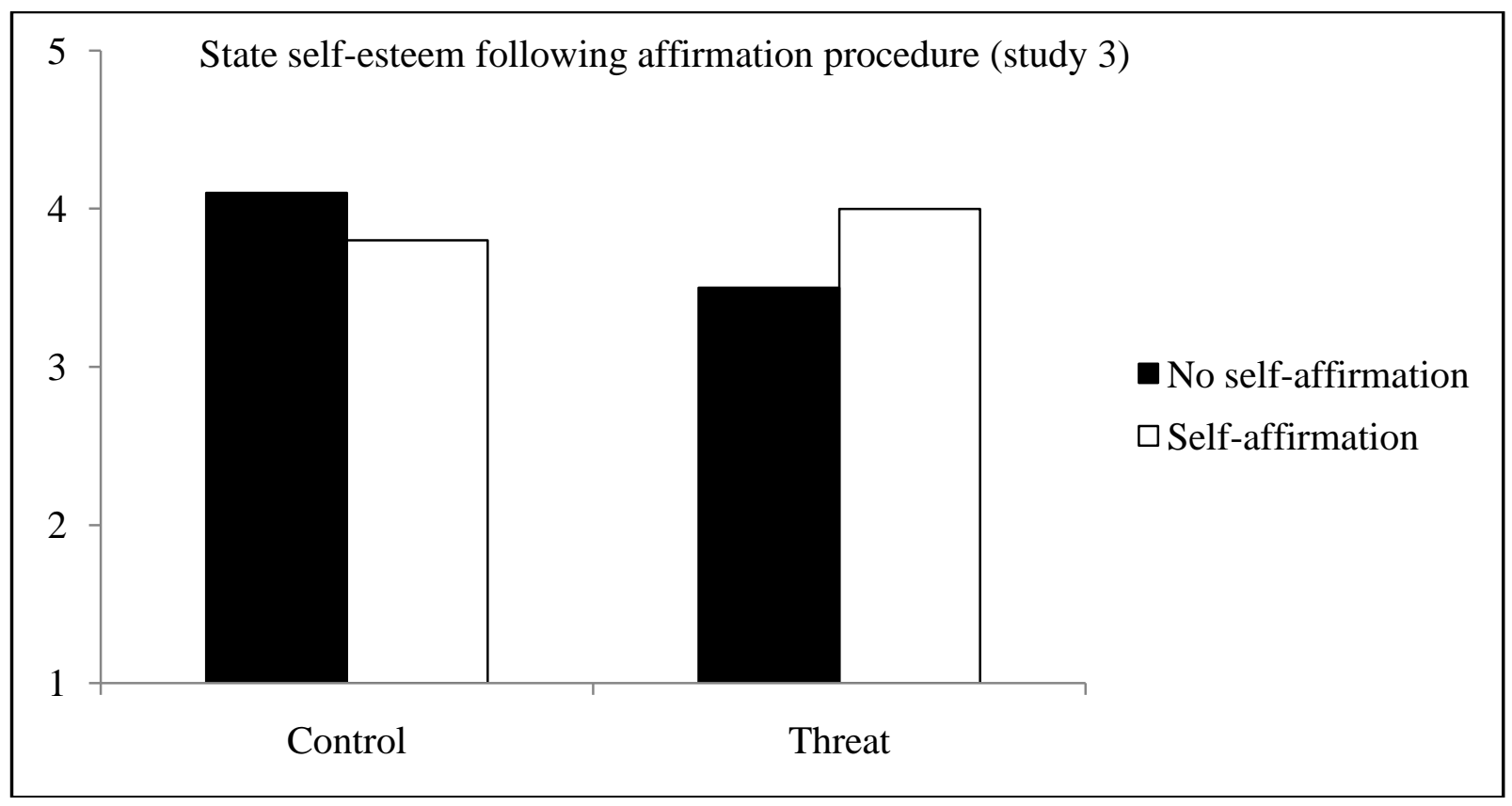


Figure 2

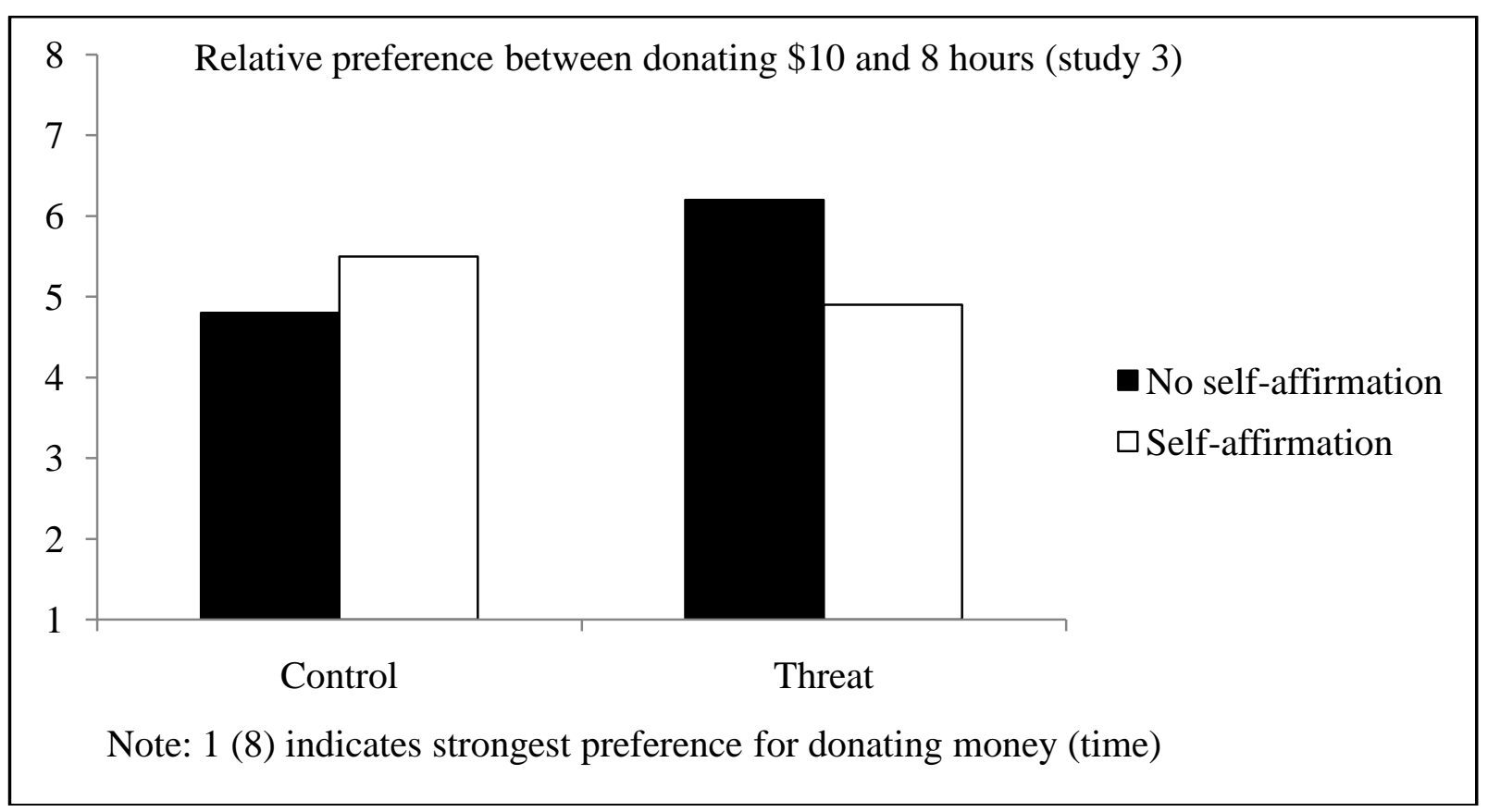


Figure 3

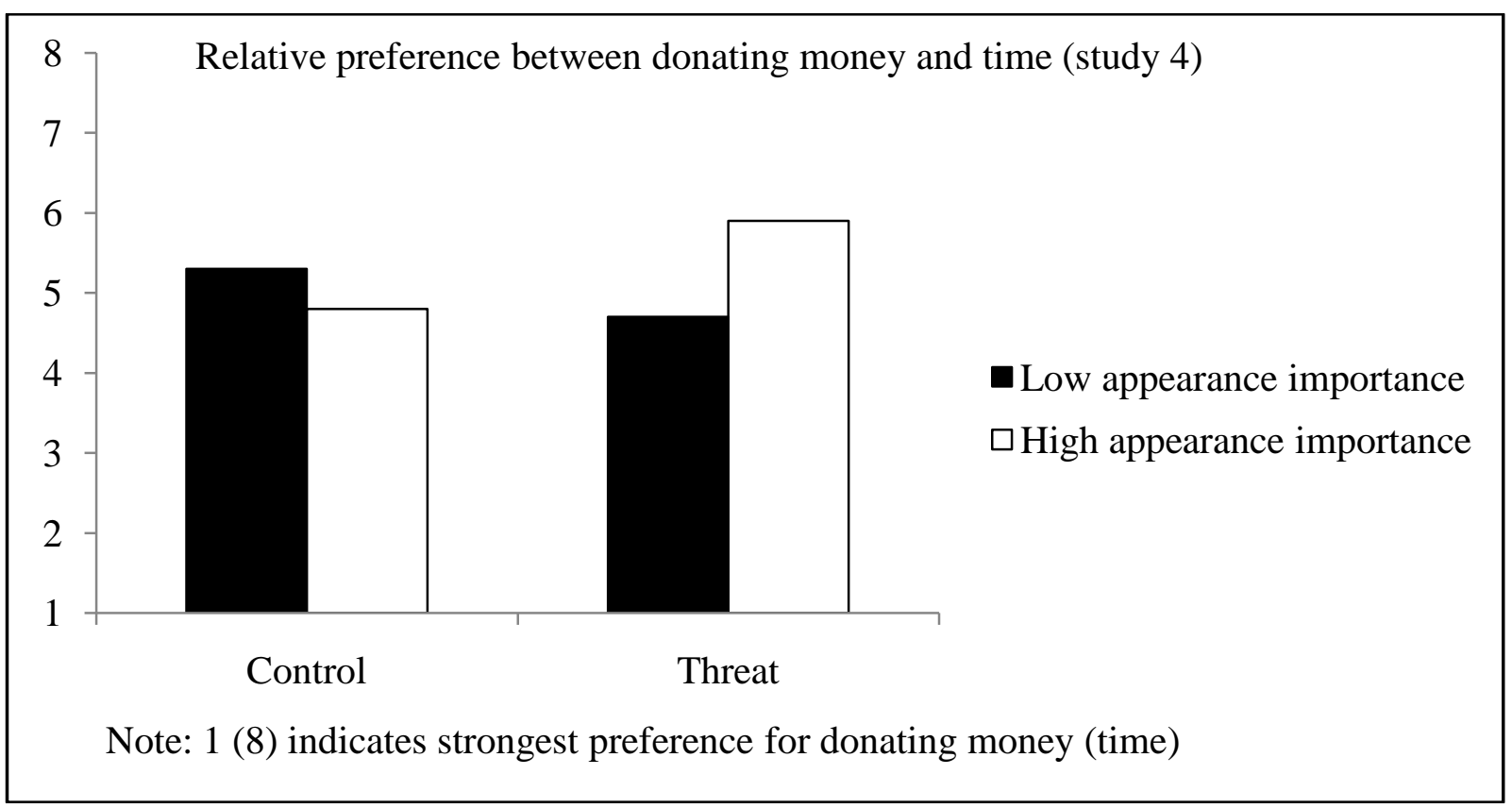


Figure 4

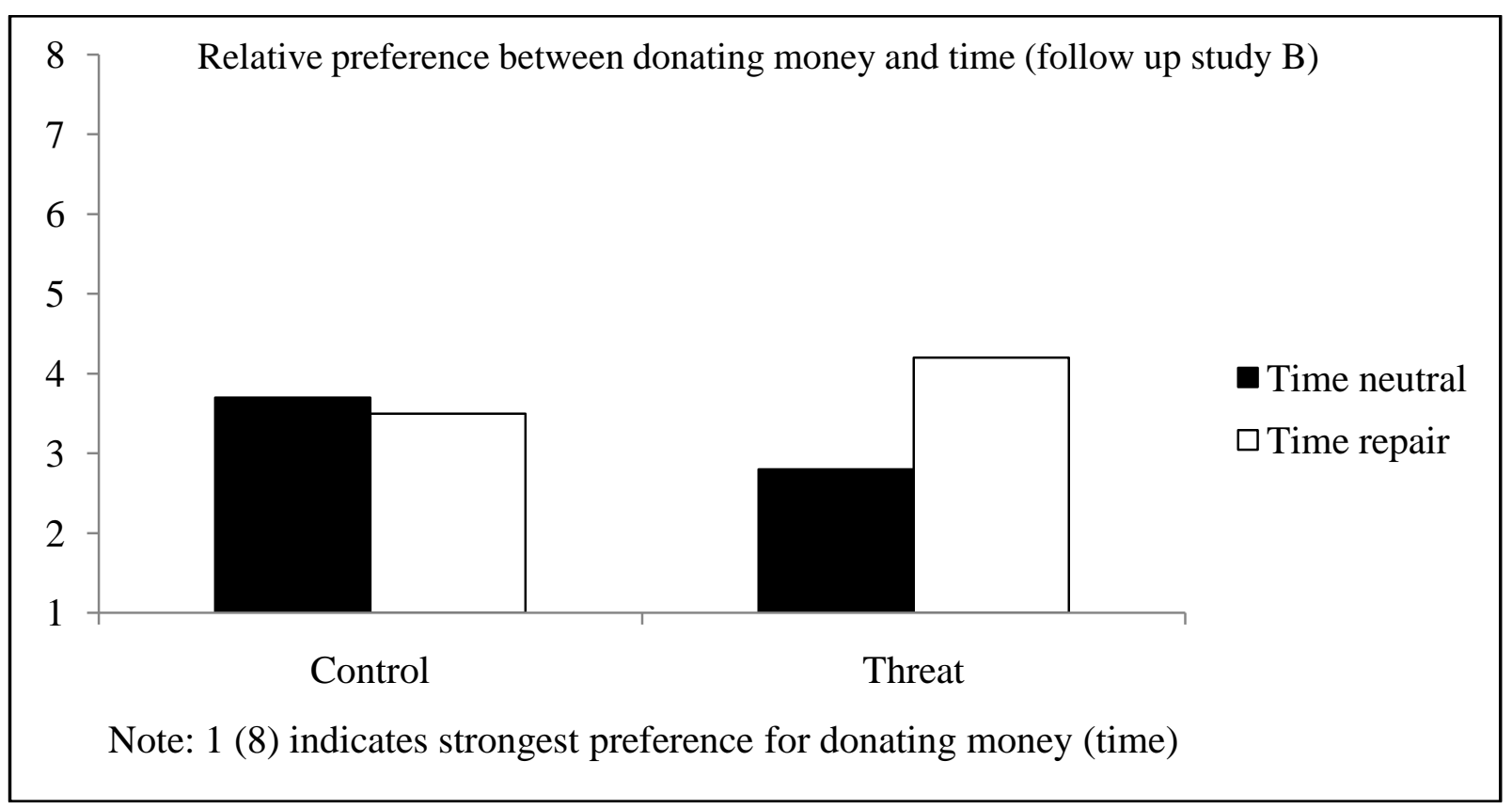




\section{Appendices}

\section{Appendix 1: Handwriting manipulation (studies 1 and 2)}

\section{Graphology study}

This study was designed to investigate the validity of graphology in predicting academic performance. This study is only experimental and intends to assess your potential as a student and later as a business professional.

Instructions: Please [use your non-dominant hand (i.e., your left hand if you are right-handed, or your right hand if you are left-handed) to] write an essay about your intelligence in the space provided below. Make sure to develop at least 3 points illustrating why you think you are intelligent. Your essay should be 100 words long (+ or $-10 \%)$. 
Appendix 2: Volunteerism survey (study 1)

\section{Volunteerism survey}

This survey intends to capture people's true feelings and attitudes about volunteerism. Please answer the following questions genuinely. There is no right or wrong answer. We are only interested in your genuine response. Thank you.

1. What would you be more likely to do? (circle a number)

$\begin{aligned} & \text { Give } \$ 10 \text { to your } \\
& \text { favorite charity }\end{aligned}$
\begin{tabular}{|c|c|c|c|c|c|c|c|}
\hline 1 & 2 & 3 & 4 & 5 & 6 & $\begin{array}{c}\text { Volunteer } 1 \text { day of work } \\
\text { to your favorite charity }\end{array}$ \\
\hline
\end{tabular}

2. What would you be more likely to do? (circle a number)

$\begin{aligned} & \text { Give } \$ 30 \text { to your } \\
& \text { favorite charity }\end{aligned} \begin{gathered}\text { Volunteer } 1 \text { day of work } \\
\text { to your favorite charity }\end{gathered}$
\begin{tabular}{|c|c|c|c|c|c|c|c|}
\hline 1 & 2 & 3 & 4 & 5 & 6 & 7 & 8 \\
\hline
\end{tabular}

3. What would you be more likely to do? (circle a number)

$\begin{aligned} & \text { Give } \$ 50 \text { to your } \\
& \text { favorite charity }\end{aligned}$
\begin{tabular}{|c|c|c|c|c|c|c|c|}
\hline $\begin{array}{l}\text { Volunteer } 1 \text { day of work } \\
\text { to your favorite charity }\end{array}$ \\
\hline 1 & 2 & 3 & 4 & 5 & 6 & 7 & 8 \\
\hline
\end{tabular}

4. What would you be more likely to do? (circle a number)

Give $\$ 70$ to your

favorite charity

\begin{tabular}{|c|c|c|c|c|c|c|c|}
\hline 1 & 2 & 3 & 4 & 5 & 6 & 7 & 8 \\
\hline
\end{tabular}

5. What would you be more likely to do? (circle a number)

$\begin{aligned} & \text { Give } \$ 90 \text { to your } \\
& \text { favorite charity }\end{aligned}$
\begin{tabular}{|c|c|c|c|c|c|c|c|}
\hline 1 & 2 & 3 & 4 & 5 & 6 & $\begin{array}{c}\text { Volunteer } 1 \text { day of work } \\
\text { to your favorite charity }\end{array}$ \\
\hline
\end{tabular}

6. What would you be more likely to do? (circle a number)

Give $\$ 110$ to your
favorite charity
\begin{tabular}{|c|c|c|c|c|c|c|c|}
\hline 1 & 2 & 3 & 4 & 5 & 6 & 7 & $\begin{array}{c}\text { Volunteer } 1 \text { day of work } \\
\text { to your favorite charity }\end{array}$ \\
\hline
\end{tabular}


7. What would you be more likely to do? (circle a number)

$\begin{aligned} & \text { Give } \$ 130 \text { to your } \\
& \text { favorite charity }\end{aligned}$
\begin{tabular}{|c|c|c|c|c|c|c|c|}
\hline 1 & 2 & 3 & 4 & 5 & 6 & $\begin{array}{c}\text { Volunteer } 1 \text { day of work } \\
\text { to your favorite charity }\end{array}$ \\
\hline
\end{tabular}

8. In general, would you rather volunteer time or give money to your favorite charity?

I'd rather I'd rather
give money volunteer time

\begin{tabular}{|l|l|l|l|l|l|l|l|}
\hline 1 & 2 & 3 & 4 & 5 & 6 & 7 & 8 \\
\hline
\end{tabular}

9. Name below one charitable organization that defends/promotes a cause important to you. 
Appendix 3: Word Integration Task (study 3)

\section{Word Integration Task}

Instructions - Part 1: Please direct your attention to the examples below. Each example offers 3 stimulus words. The goal of this study is to generate a fourth word, which, when combined with each of the three stimulus words, would result in word pairs that are a common compound word or phrase. There can only be one answer per word problem.

Example 1: cottage/swiss/cake

$\rightarrow$ Answer: cheese as in cottage cheese, swiss cheese, cheese cake

Example 2: cream/skate/water

$\rightarrow$ Answer: ice as in ice cream, ice skate, ice water

Example 3: $\quad$ show/life/row

$\rightarrow$ Answer: boat as in boat show, life boat, row boat

Instructions - Part 2: On the next page, you will find 12 word problems and be given exactly $\underline{6 \text { minutes }}$ (about 30 seconds per problem) to complete the task.

\section{STOP!}

Please wait for the experimenter's instructions before turning the page. 
You may now start. Remember that you will have no more than 6 minutes to complete the task. There can only be one answer per word problem.

1. dust/cereal/fish $\rightarrow$

2. palm/shoe/house $\rightarrow$

3. wheel/hand/shopping $\rightarrow$

4. mill/tooth/dust $\rightarrow$

5. fly/clip/wall $\rightarrow$

6. wagon/break/radio $\rightarrow$

7. dress/dial/flower $\rightarrow$

8. animal/back/rat $\rightarrow$

9. house/thumb/pepper $\rightarrow$

10. master/toss/finger $\rightarrow$

11. blank/list/mate $\rightarrow$

12. iron/shovel/engine $\rightarrow$

STOP after 6 minutes! 
Word integration task: Answer key

\begin{tabular}{|l|lll|}
\hline 1. & dust/cereal/fish & $\rightarrow$ bowl \\
\hline 2. & palm/shoe/house & $\rightarrow$ tree \\
\hline 3. & wheel/hand/shopping & $\rightarrow$ cart \\
\hline 4. & mill/tooth/dust & $\rightarrow$ saw \\
\hline 5. & fly/clip/wall & $\rightarrow$ paper \\
\hline 6. & wagon/break/radio & $\rightarrow$ station \\
\hline 7. & dress/dial/flower & $\rightarrow$ sun \\
\hline 8. & animal/back/rat & $\rightarrow$ pack \\
\hline 9. & house/thumb/pepper & $\rightarrow$ green \\
\hline 10. & master/toss/finger & $\rightarrow$ ring \\
\hline 11. & blank/list/mate & $\rightarrow$ check \\
\hline 12. & iron/shovel/engine & $\rightarrow$ steam \\
\hline
\end{tabular}

Performance table (threat condition)

\begin{tabular}{|l|l|}
\hline Top third & $11-12$ solved \\
\hline Middle third & $9-10$ solved \\
\hline Bottom third & $0-8$ solved \\
\hline
\end{tabular}

(control condition)

\begin{tabular}{|l|l|}
\hline Top third & $11-12$ solved \\
\hline Middle third & $9-10$ solved \\
\hline Bottom third & $0-8$ solved \\
\hline
\end{tabular}

Above is the answer key to the word integration task you just completed. Please go back to your answers and report below the exact number of correct answers you had.

$\rightarrow$ I had correct answers.

Please refer to the performance table above and indicate which performance group you belong to based on the number of correct answers you had. (check one)

$\rightarrow$ My performance places me in the __ Top third

Middle third

Bottom third

Circle one number on the scale below to indicate how difficult you found this word integration task.

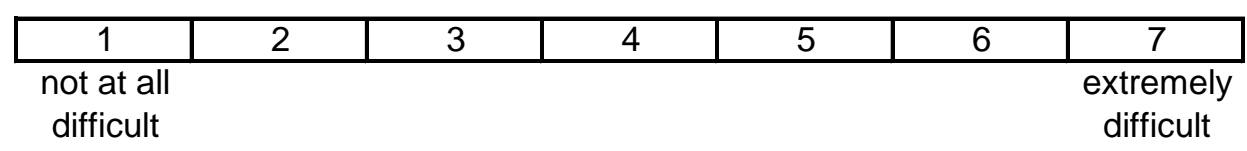


Appendix 4: Heatherton \& Polivy's (1991) scale of state self-esteem (study 3)

Instructions: The next few questions intend to measure what you are thinking at this moment. There is, of course, no right answer for any statement. The best answer is what you feel is true of yourself at this moment. Be sure to answer all of the items, even if you are not certain of the best answer. Again, answer these questions as they are true for you RIGHT NOW.

\begin{tabular}{|l|l|l|l|l|}
\hline 1 & 2 & 3 & 4 & 5 \\
\hline Not at all & A little bit & Somewhat & Very much & Extremely \\
\hline
\end{tabular}

\begin{tabular}{|l|l|l|}
\multicolumn{2}{l|}{} & $\begin{array}{l}\text { Enter } \\
\text { a number } \\
\text { here }\end{array}$ \\
\hline 1 & I feel confident about my abilities. & \\
\hline 2 & I feel frustrated or rattled about my performance. & \\
\hline 3 & I feel that I am having trouble understanding things that I read. & \\
\hline 4 & I feel as smart as others. & \\
\hline 5 & I feel confident that I understand things. & \\
\hline 6 & I feel that I have less scholastic ability right now than others. & \\
\hline 7 & I feel like I'm not doing well. & \\
\hline
\end{tabular}


Appendix 5: Self-affirmation procedure - No self-affirmation condition (study 3)

Memory study: This study is interested in how well people can remember events of their personal lives.

Part I: Ranking of Personal Characteristics and Values

Below is a list of characteristics and values, some of which may be important to you, some of which may be unimportant. Please rank these values and qualities in order of importance to you, from 1 to $11(1=$ most important, $11=$ least important $)$. Make sure to use each number only once!

Artistic skills/aesthetic appreciation

Sense of humor

Relations with friends/family

Spontaneity/living life in the moment

Social skills

Athletics

Music al ability/appreciation

Physical attractiveness

Creativity

Business/managerial skills

Romantic values

\section{Part II: Short essay}

In the space provided below, please explain why your $9^{\text {th }}$ ranked value might be important to someone else, and describe in detail one instance where expressing or acting on this particular value may cause someone else to feel good about themselves. As you describe this experience, make sure to reflect on why this experience may provide someone else with personal satisfaction. Your essay should be 50 to 100 words long. 
Appendix 6: Self-affirmation procedure -Self-affirmation condition (study 3)

Memory study: This study is interested in how well people can remember events of their personal lives.

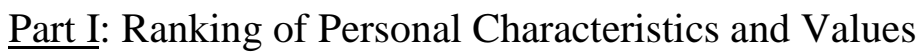

Below is a list of characteristics and values, some of which may be important to you, some of which may be unimportant. Please rank these values and qualities in order of importance to you, from 1 to 11 ( 1 = most important, $11=$ least important $)$. Make sure to use each number only once!

Artistic skills/aesthetic appreciation

Sense of humor

Relations with friends/family

Spontaneity/living life in the moment

Social skills

Athletics

Music al ability/appreciation

Physical attractiveness

Creativity

Business/managerial skills

Romantic values

\section{Part II: Short essay}

In the space provided below, please explain why your $\underline{1}^{\text {st }}$ ranked value is important to you, and recall in detail one instance where expressing or acting on this particular value has caused you to feel good about yourself. As you describe this experience, make sure to reflect on why this experience provides you with personal satisfaction. Your essay should be 50 to 100 words long. 
Appendix 7: Robins et al.'s (2001) measure of state self-esteem (study 3)

Instructions: Circle one number on the scale below to indicate the extent to which you agree or disagree with the following statement:

I feel I have high self-esteem right now.

\begin{tabular}{|c|c|c|c|c|}
\hline 1 & 2 & 3 & 4 & 5 \\
\hline
\end{tabular}




\section{Appendix 8: Picture study - Threat condition for women (study 4)}

\section{Picture study}

Instructions: We selected pictures of college students from a popular website and pasted them thereafter. Please review this assortment of photographs and indicate for each picture how attractive the person is compared to you . Please try to be as accurate as possible. Using a "third person" approach may help. For instance, if someone other than you were to judge your attractiveness vs. that of the person depicted, what would they say?

Go to the next page. 
Picture 1

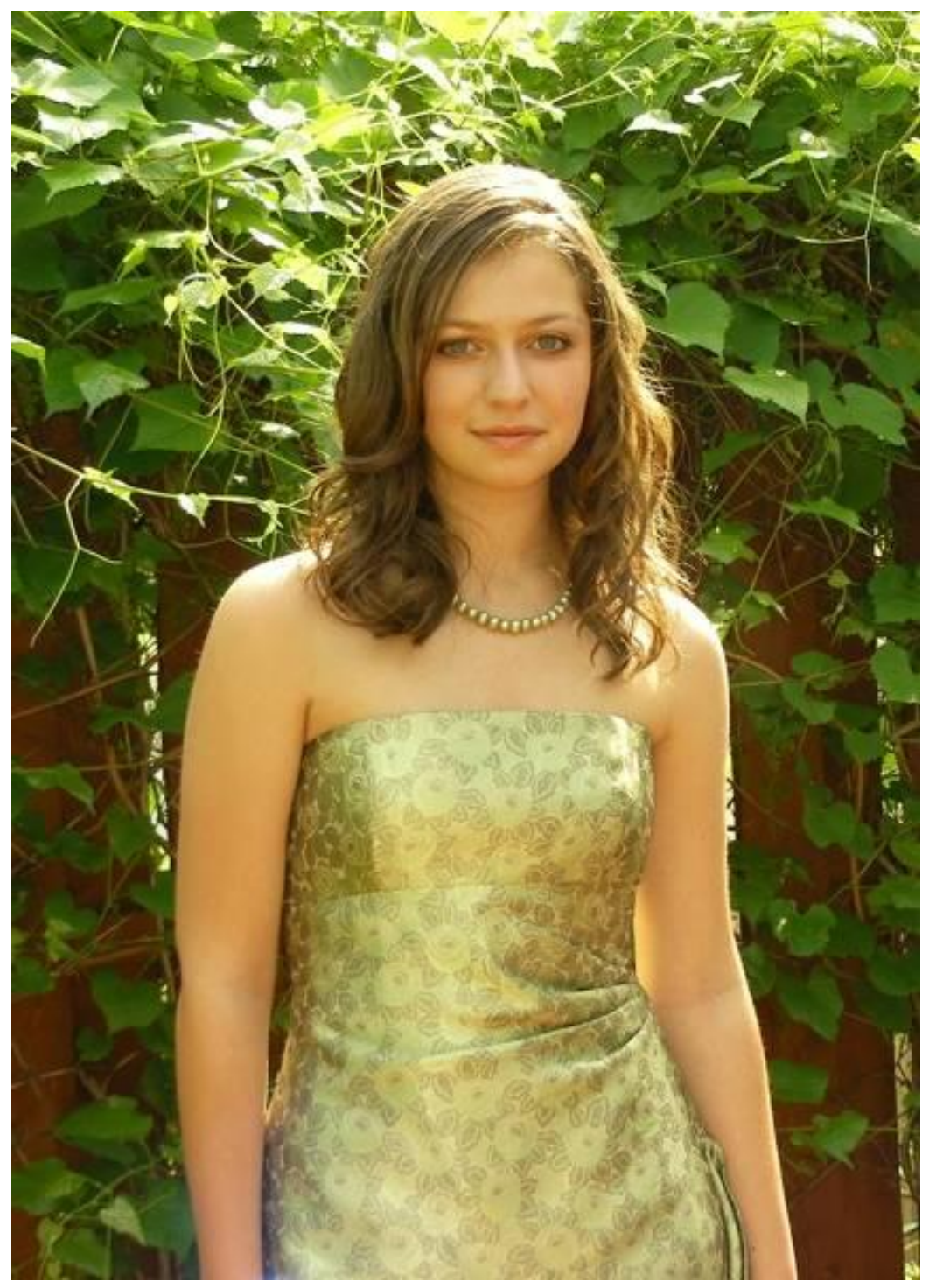

Compared to this person, I am... (circle one number)

\begin{tabular}{|c|c|c|c|c|c|c|c|c|}
\hline 1 & 2 & 3 & 4 & 5 & 6 & 7 & 8 & 9 \\
\hline
\end{tabular}
Not at all active


Picture 2

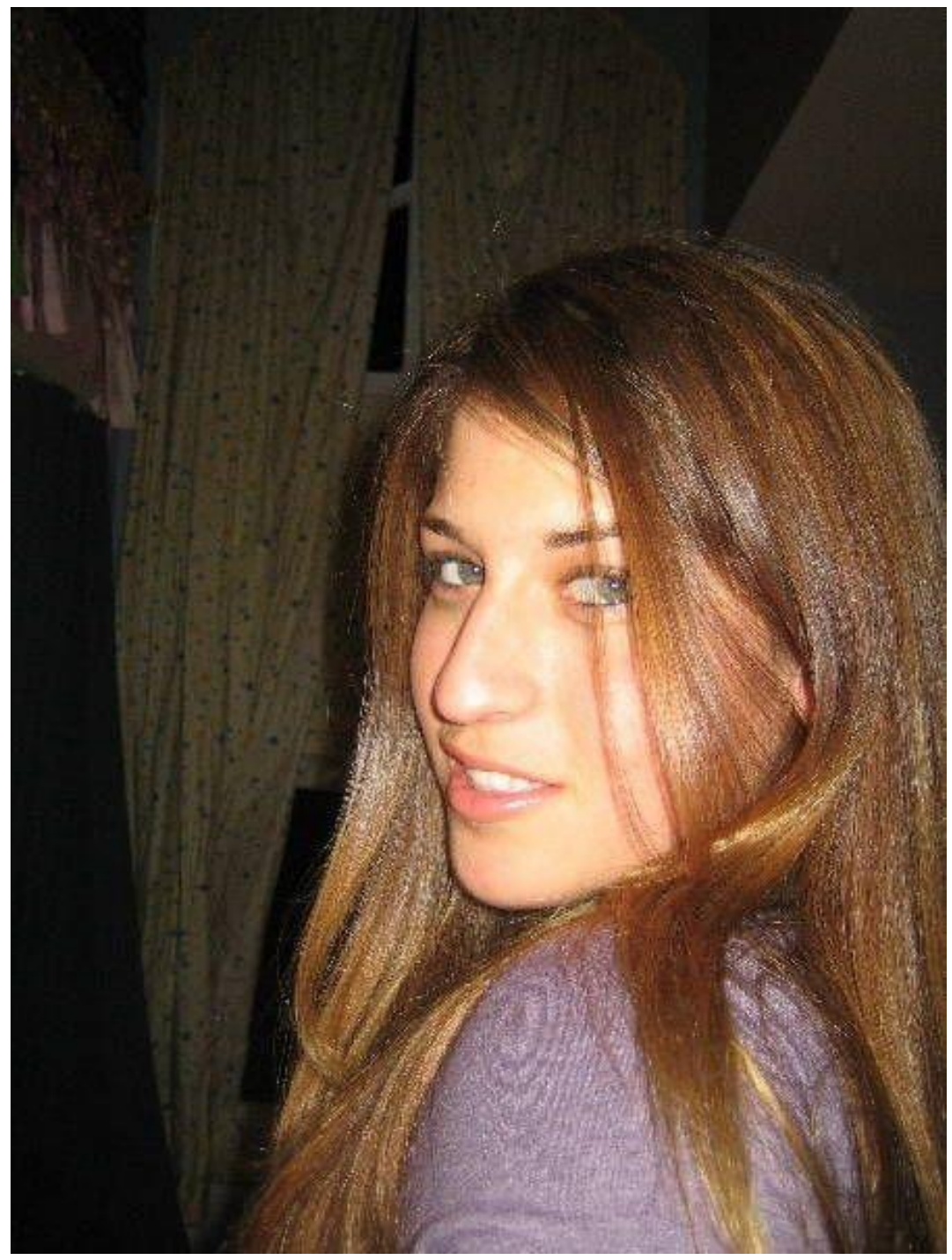

Compared to this person, I am... (circle one number)

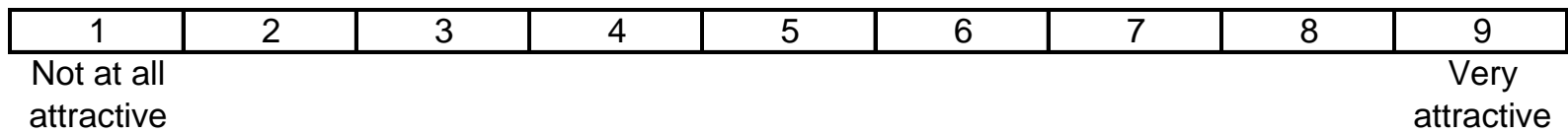


Picture 3

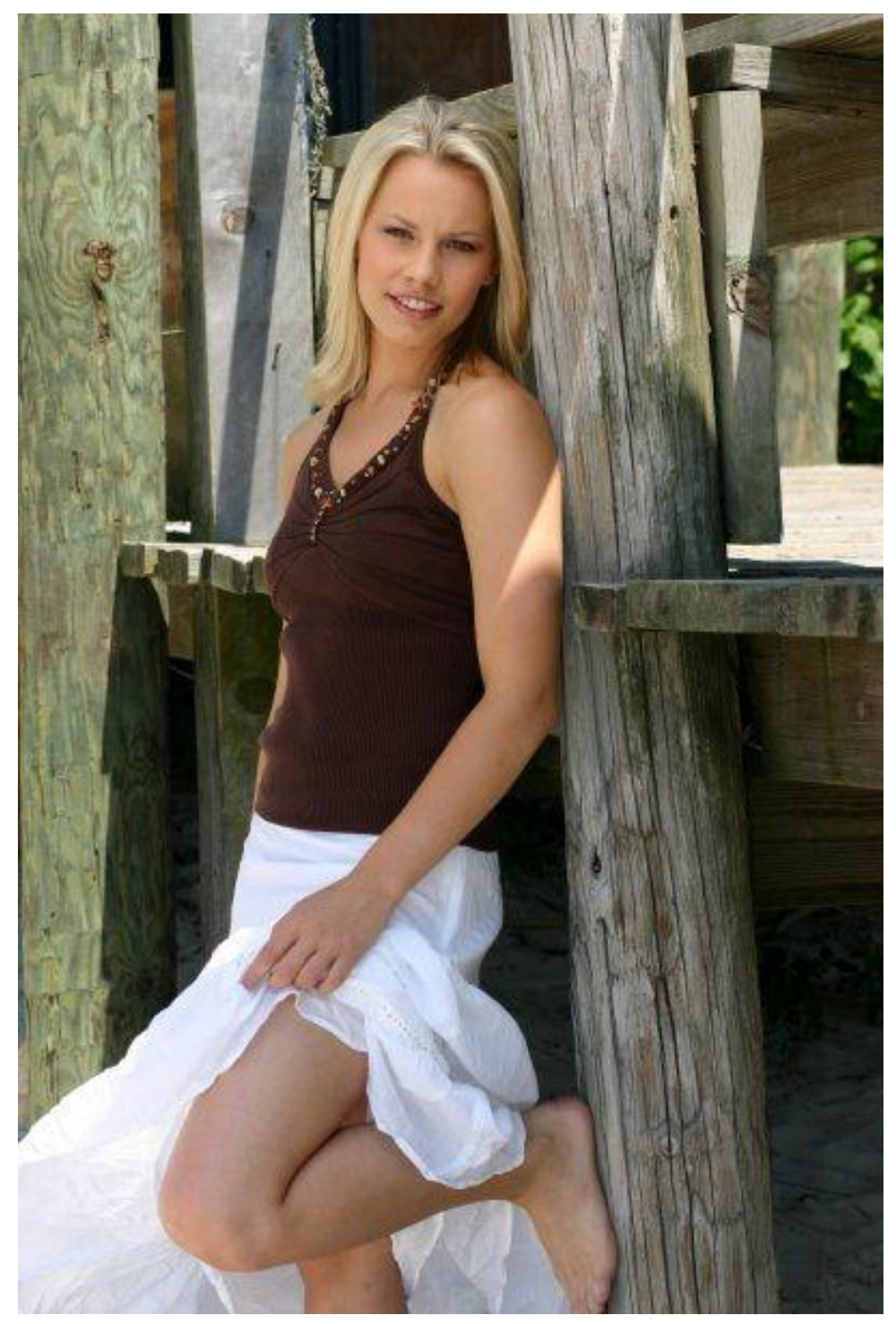

Compared to this person, I am... (circle one number)

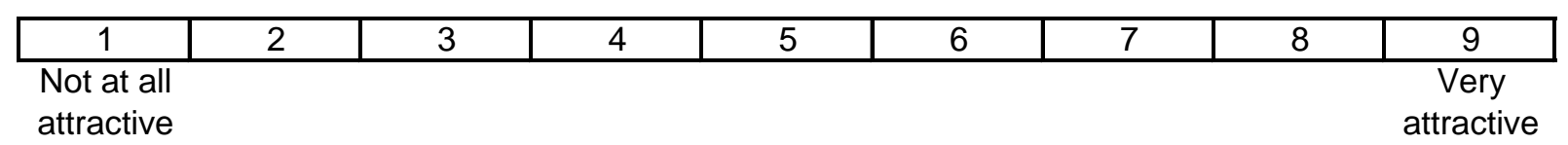


Picture 4

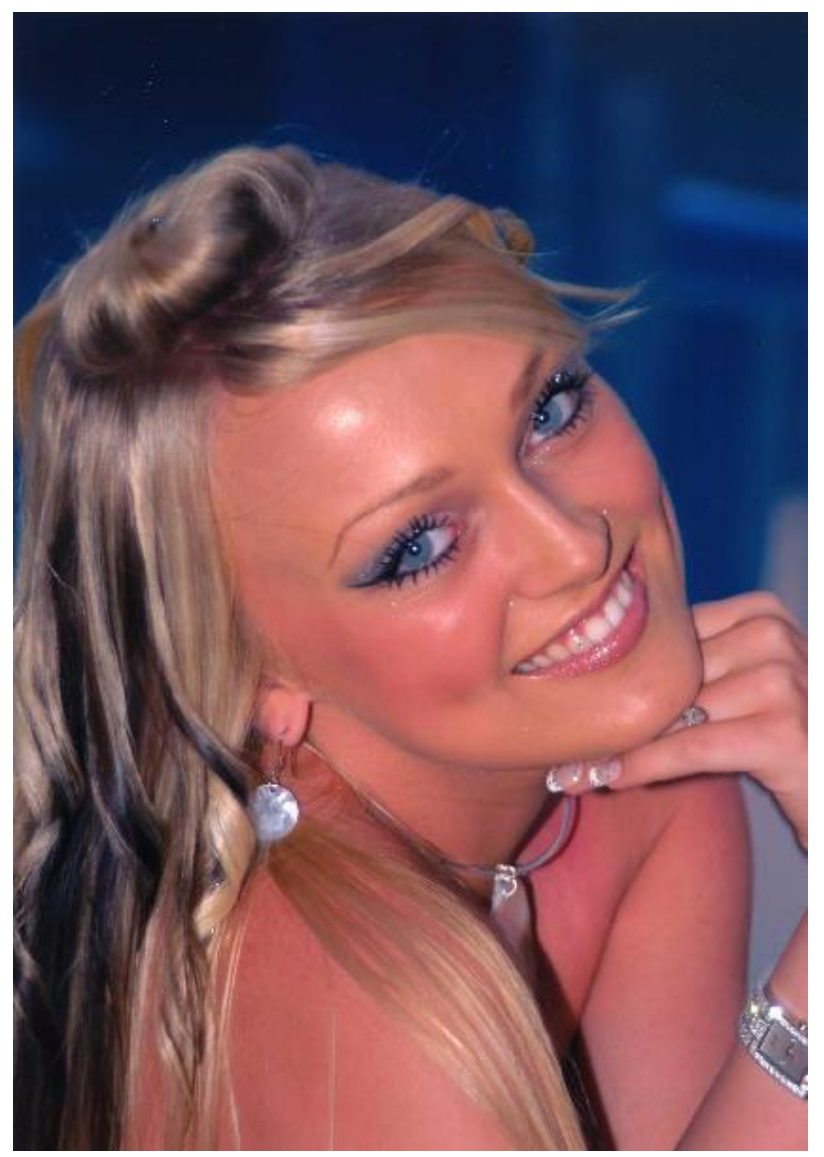

Compared to this person, I am... (circle one number)

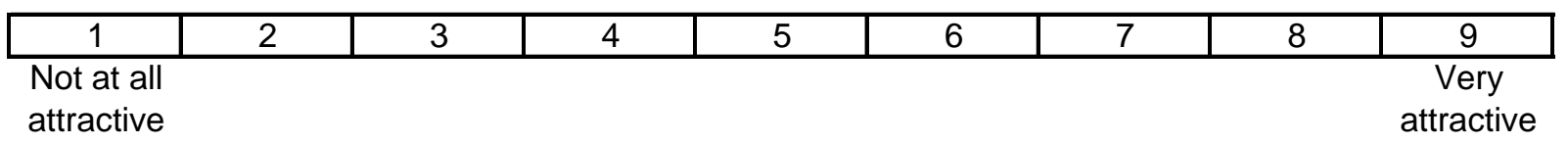


Picture 5

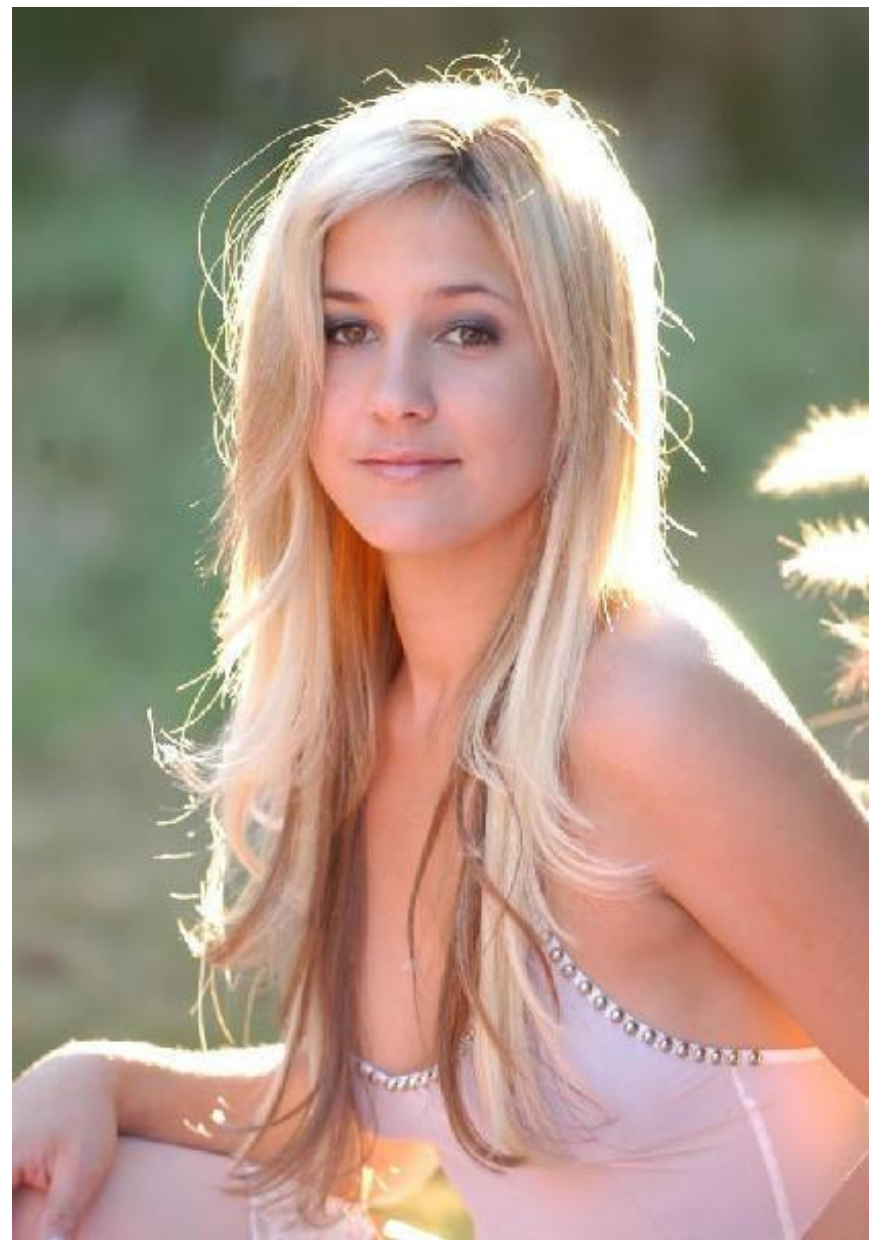

Compared to this person, I am... (circle one number)

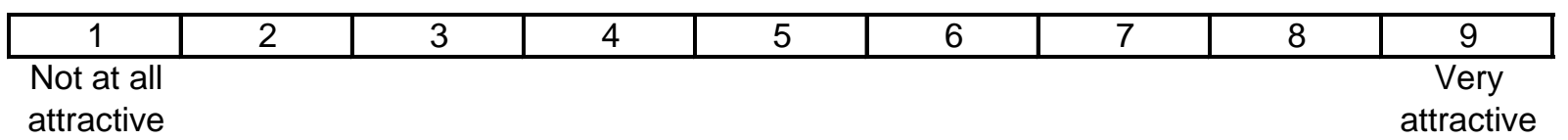


Demographics:

Circle your gender: $\quad$ Female Male

Age:

Overall, that is without specific comparison, how attractive would you say you are?

\begin{tabular}{|c|c|c|c|c|c|c|c|c|}
\hline 1 & 2 & 3 & 4 & 5 & 6 & 7 & 8 & 9 \\
\hline
\end{tabular}
Not at all
attractive

Thank you. You can now proceed to the next study. 
Appendix 9: Picture study - Threat condition for men (study 4)

Picture study

Instructions: We selected pictures of college students from a popular website and pasted them thereafter. Please review this assortment of photographs and indicate for each picture how attractive the person is compared to you. Please try to be as accurate as possible. Using a "third person" approach may help. For instance, if someone other than you were to judge your attractiveness vs. that of the person depicted, what would they say?

Go to the next page. 
Picture 1

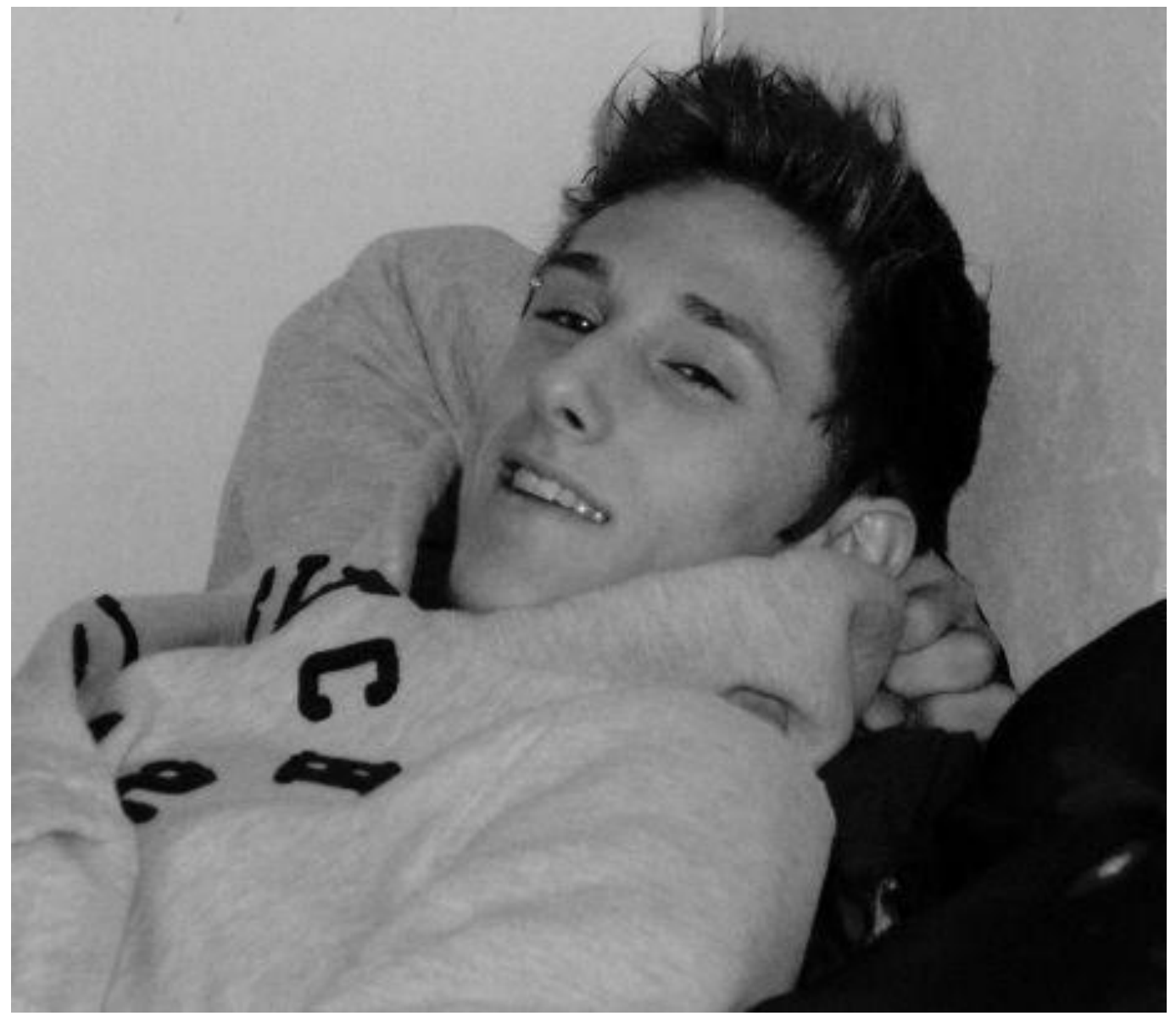

Compared to this person, I am... (circle one number)

\begin{tabular}{|c|c|c|c|c|c|c|c|c|}
\hline 1 & 2 & 3 & 4 & 5 & 6 & 7 & 8 & 9 \\
\hline
\end{tabular}
Not at all
attactive


Picture 2

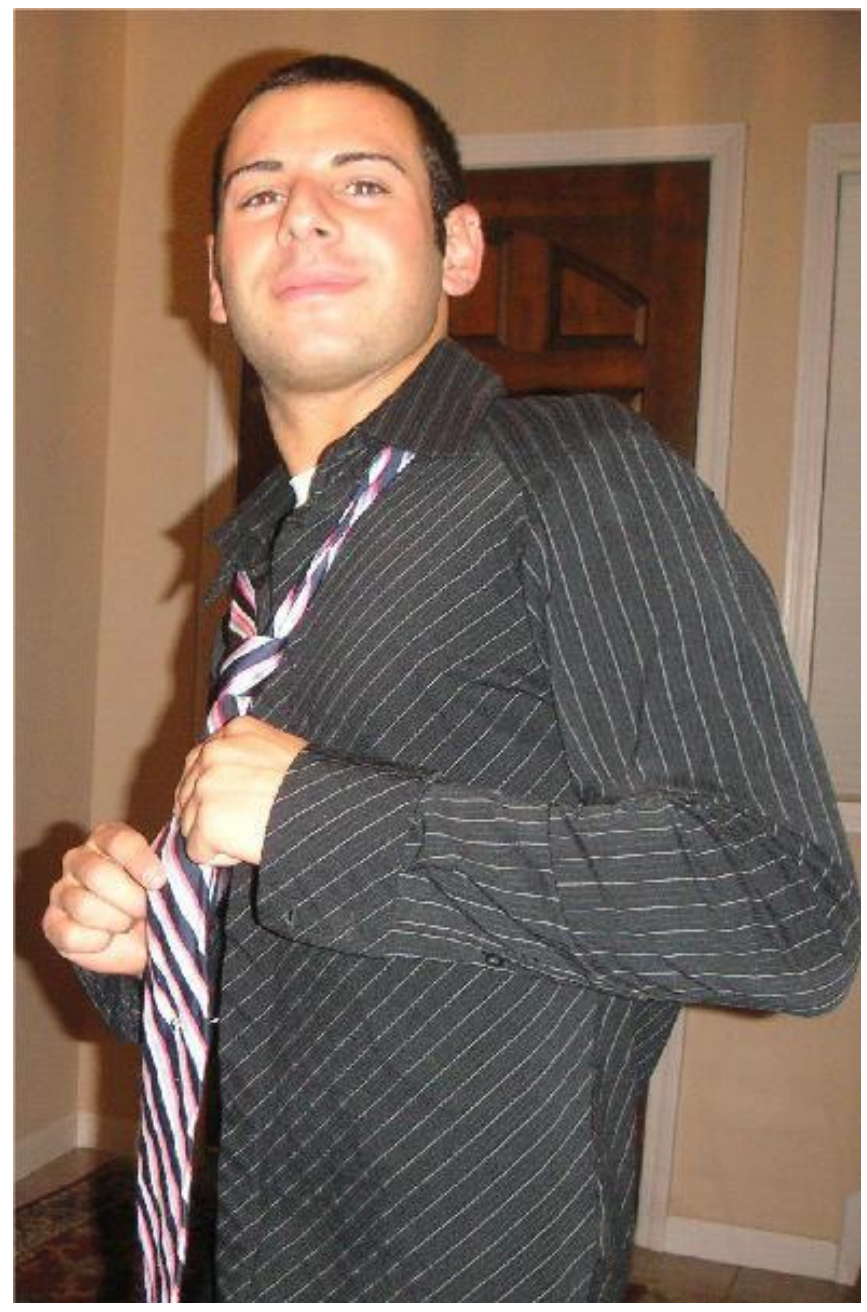

Compared to this person, I am... (circle one number)

\begin{tabular}{|c|c|c|c|c|c|c|c|c|}
\hline 1 & 2 & 3 & 4 & 5 & 6 & 7 & 8 & 9 \\
\hline
\end{tabular}
Not at all
attractive


Picture 3

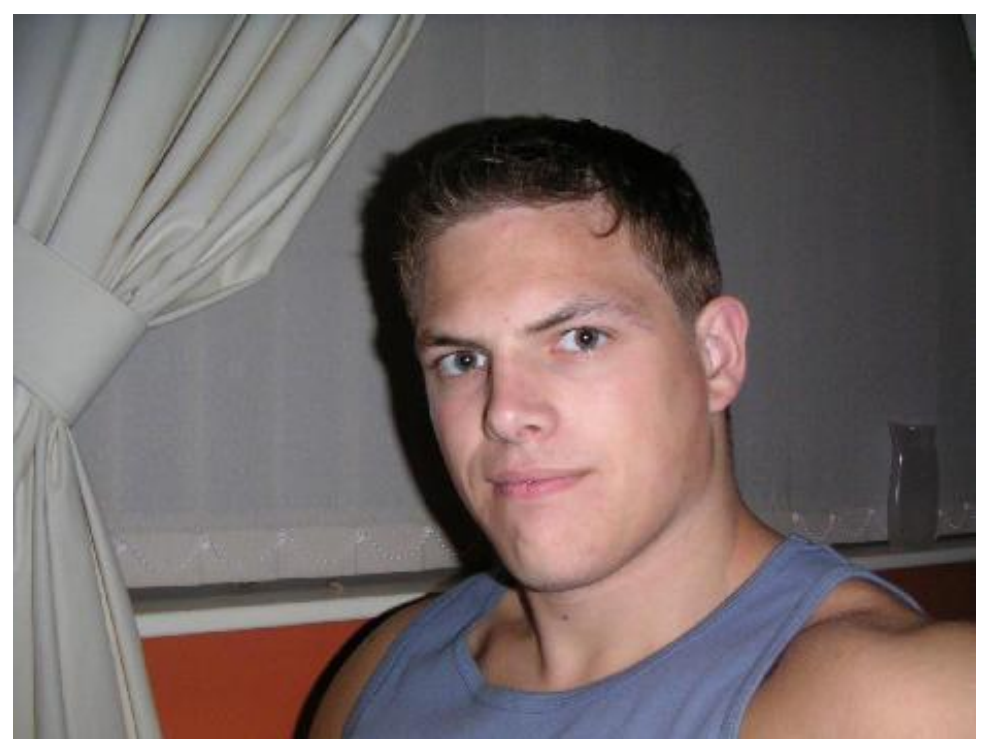

Compared to this person, I am... (circle one number)

\begin{tabular}{l|l|l|l|l|l|l|l|c|}
\hline 1 & 2 & 3 & 4 & 5 & 6 & 7 & 8 & 9 \\
\hline Not at all \\
attractive
\end{tabular}


Picture 4

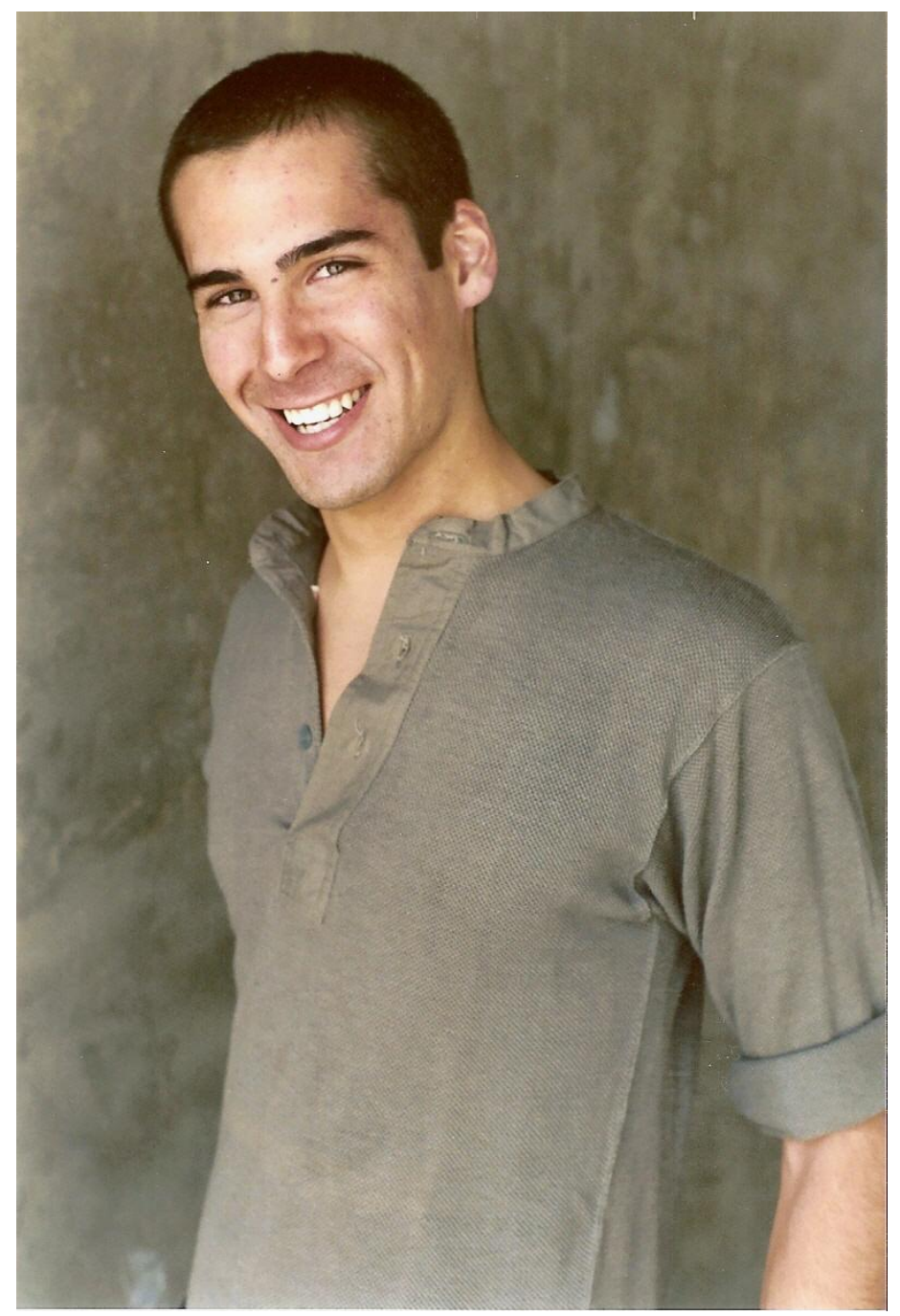

Compared to this person, I am... (circle one number)

\begin{tabular}{|c|c|c|c|c|c|c|c|c|}
\hline 1 & 2 & 3 & 4 & 5 & 6 & 7 & 8 & 9 \\
\hline $\begin{array}{l}\text { Not at } \\
\text { attrac }\end{array}$ & & & & & & & & $\begin{array}{l}\text { Ver } \\
\text { ttract }\end{array}$ \\
\hline
\end{tabular}




\section{Picture 5}

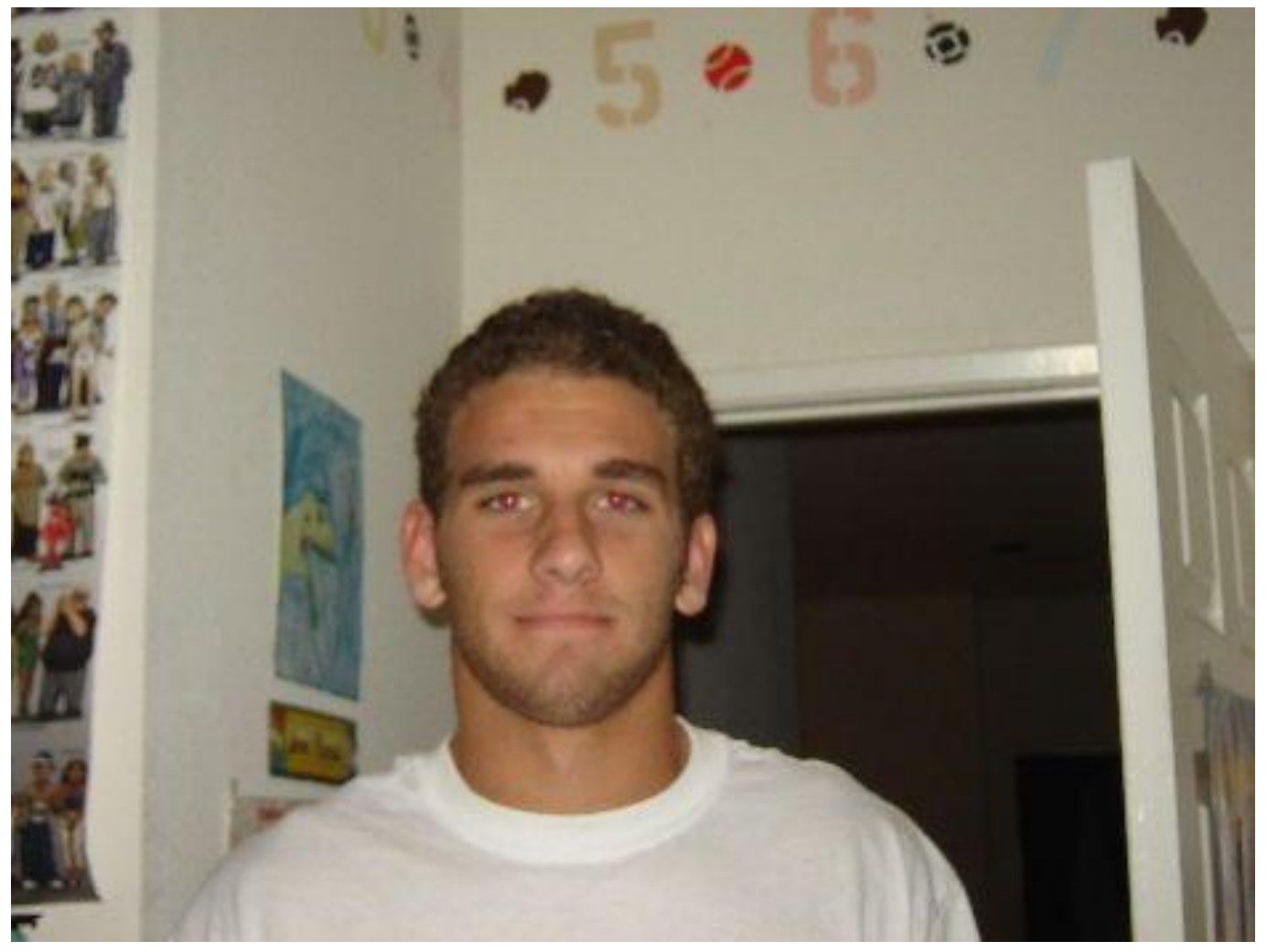

Compared to this person, I am... (circle one number)

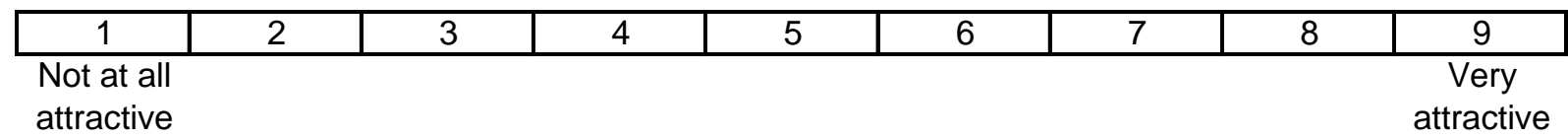


Demographics:

Circle your gender: $\quad$ Female Male

Age:

Overall, that is without specific comparison, how attractive would you say you are?

\begin{tabular}{|c|c|c|c|c|c|c|c|c|}
\hline 1 & 2 & 3 & 4 & 5 & 6 & 7 & 8 & 9 \\
\hline
\end{tabular}
Not at all
attractive

Thank you. You can now proceed to the next study. 


\section{Appendix 10: PANAS scale (study 4)}

Instructions: This scale consists of a number of words that describe different feelings and emotions. Read each item and then mark the appropriate answer in the space next to that word. Indicate to what extent you feel this way right now, that is, at the present moment. Use the following scale to record your answers.

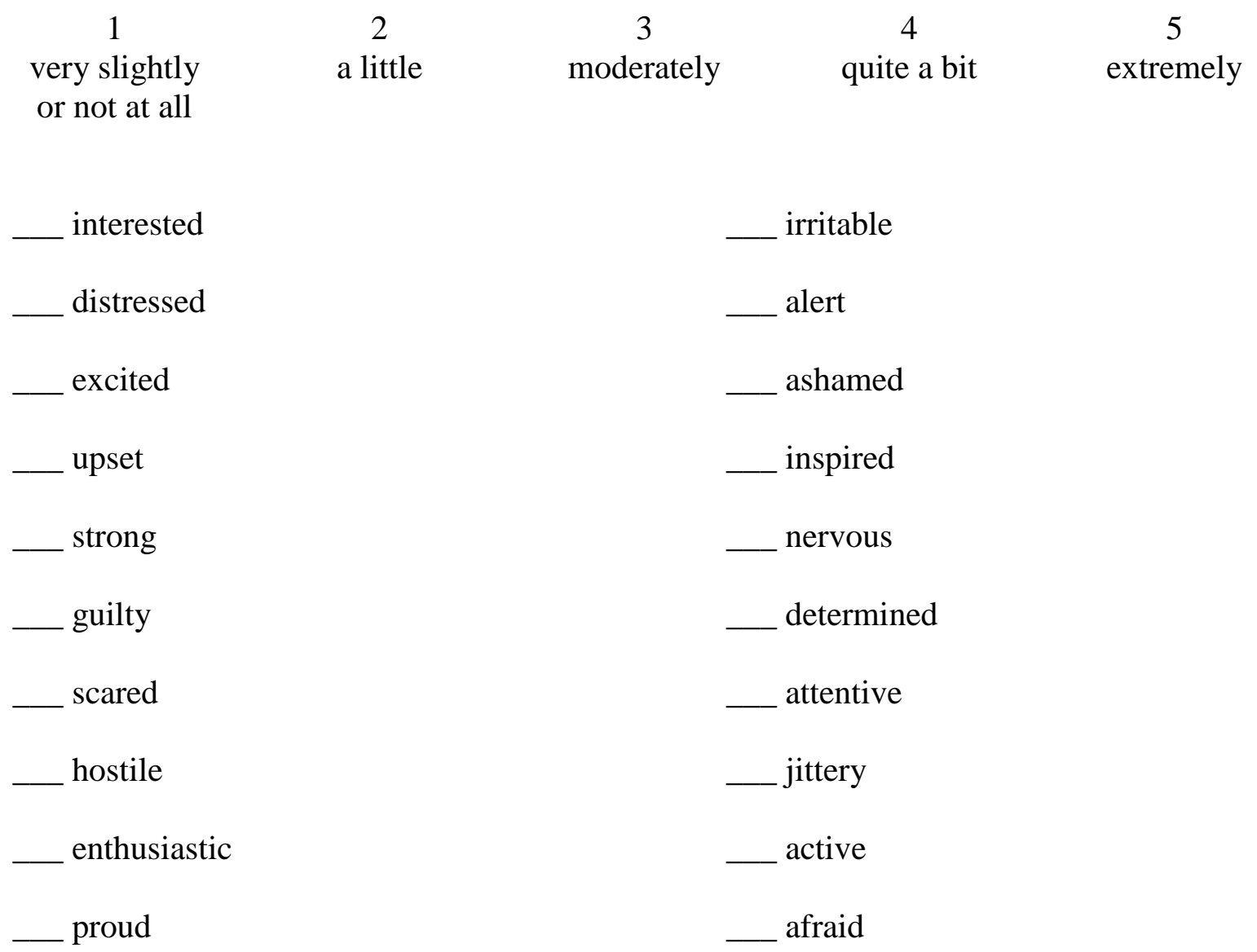


Appendix 11: Contingencies of self-worth scale by Crocker et al. (2003; study 4)

Instructions: Please respond to each of the following statements by circling your answer using the scale from " 1 = Strongly disagree" to "7 = Strongly agree." If you haven't experienced the situation described in a particular statement, please answer how you think you would feel if that situation occurred.

\begin{tabular}{|c|c|c|c|c|c|c|}
\hline 1 & 2 & 3 & 4 & 5 & 6 & 7 \\
\hline $\begin{array}{l}\text { Strongly } \\
\text { disagree }\end{array}$ & Disagree & \begin{tabular}{|l} 
Disagree \\
somewhat
\end{tabular} & Neutral & $\begin{array}{l}\text { Agree } \\
\text { somewhat }\end{array}$ & Agree & $\begin{array}{l}\text { Strongly } \\
\text { agree }\end{array}$ \\
\hline
\end{tabular}

\begin{tabular}{|l|l|l|}
\hline & & $\begin{array}{l}\text { Enter a } \\
\text { number } \\
\text { here }\end{array}$ \\
\hline 1 & When I think I look attractive, I feel good about myself. & \\
\hline 2 & My self-worth is based on God's love. & \\
\hline 3 & I feel worthwhile when I perform better than others on a task or skill. & \\
\hline 4 & My self-esteem is unrelated to how I feel about the way my body looks. & \\
\hline 5 & Doing something I know is wrong makes me lose my self-respect. & \\
\hline 6 & I don't care if other people have a negative opinion about me. & \\
\hline 7 & $\begin{array}{l}\text { Knowing that my family members love me makes me feel good about } \\
\text { myself. }\end{array}$ & \\
\hline 8 & I feel worthwhile when I have God's love. & \\
\hline 9 & I can't respect myself if others don't respect me. & \\
\hline 10 & $\begin{array}{l}\text { My self-worth is not influenced by the quality of my relationships with my } \\
\text { family members. }\end{array}$ & \\
\hline 11 & $\begin{array}{l}\text { Whenever I follow my moral principles, my sense of self-respect gets a } \\
\text { boost. }\end{array}$ & \\
\hline 12 & Knowing that I am better than others on a task raises my self-esteem. & \\
\hline 13 & My opinion about myself isn't tied to how well I do in school. & \\
\hline 14 & I couldn't respect myself if I didn't live up to a moral code. & \\
\hline 15 & I don't care what other people think of me. & \\
\hline 16 & $\begin{array}{l}\text { When my family members are proud of me, my sense of self-worth } \\
\text { increases. }\end{array}$ & $\begin{array}{l} \\
\text { My self-esteem is influenced by how attractive I think my face or facial }\end{array}$ \\
\hline 18 & My self-esteem would suffer if I didn't have God's love. & \\
\hline 19 & Doing well in school gives me a sense of self-respect. & \\
\hline 20 & Doing better than others gives me a sense of self-respect. & \\
\hline
\end{tabular}




\begin{tabular}{|c|c|c|c|c|c|c|}
\hline 1 & 2 & 3 & 4 & 5 & 6 & 7 \\
\hline $\begin{array}{l}\text { Strongly } \\
\text { disagree }\end{array}$ & Disagree & \begin{tabular}{|l} 
Disagree \\
somewhat
\end{tabular} & Neutral & \begin{tabular}{|l} 
Agree \\
somewhat
\end{tabular} & Agree & $\begin{array}{l}\text { Strongly } \\
\text { agree }\end{array}$ \\
\hline
\end{tabular}

\begin{tabular}{|l|l|l|}
\hline & & $\begin{array}{l}\text { Enter a } \\
\text { number } \\
\text { here }\end{array}$ \\
\hline 21 & My sense of self-worth suffers whenever I think I don't look good. & \\
\hline 22 & I feel better about myself when I know I'm doing well academically. & \\
\hline 23 & What others think of me has no effect on what I think about myself. & \\
\hline 24 & When I don't feel loved by my family, my self-esteem goes down. & \\
\hline 25 & $\begin{array}{l}\text { My self-worth is affected by how well I do when I am competing with } \\
\text { others. }\end{array}$ & \\
\hline 26 & My self-esteem goes up when I feel that God loves me. & \\
\hline 27 & My self-esteem is influenced by my academic performance. & \\
\hline 28 & My self-esteem would suffer if I did something unethical. & \\
\hline 29 & It is important to my self-respect that I have a family that cares about me. & \\
\hline 30 & My self-esteem does not depend on whether or not I feel attractive. & \\
\hline 31 & When I think that I'm disobeying God, I feel bad about myself. & \\
\hline 32 & My self-worth is influenced by how well I do on competitive tasks. & \\
\hline 33 & I feel bad about myself whenever my academic performance is lacking. & \\
\hline 34 & $\begin{array}{l}\text { My self-esteem depends on whether or not I follow my moral/ethical } \\
\text { principles. }\end{array}$ & \\
\hline 35 & My self-esteem depends on the opinions others hold of me. & \\
\hline
\end{tabular}


Appendix 12: Pictures in advertising - Control condition (follow-up study A)

Instructions: Please take a moment to look at this picture and imagine in as much detail as possible what the life of this dog must be like. Next, in the space provided below, please reflect on your current feelings and attitudes as you contemplate this image.

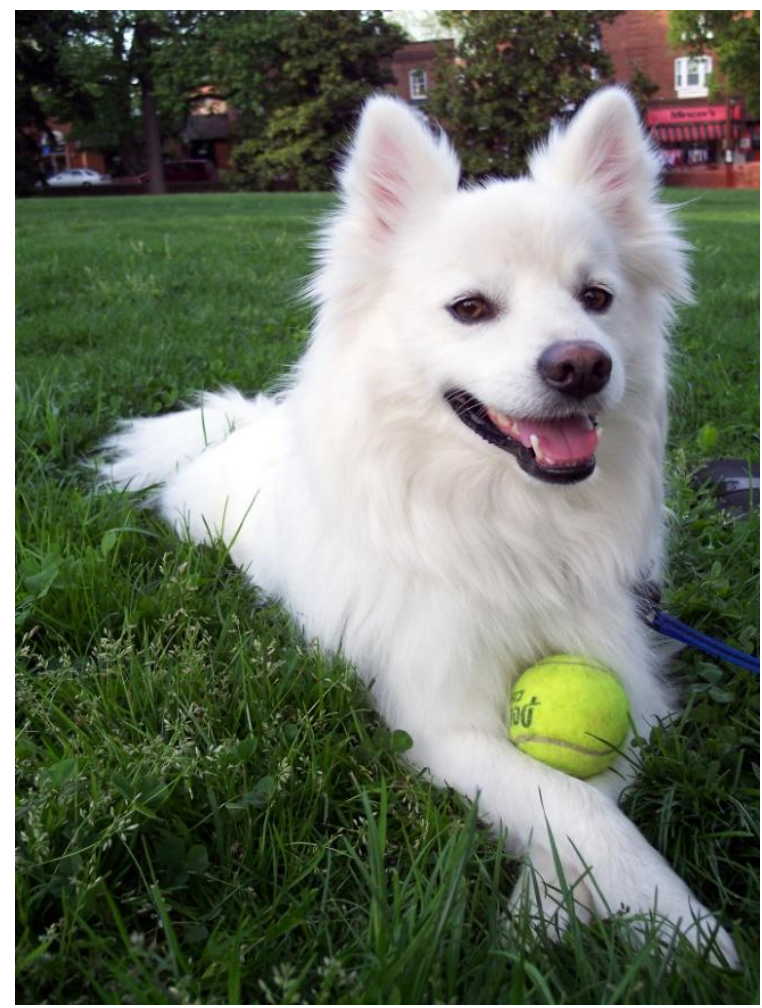

I imagine that the life of this animal is...

Very unpleasant \begin{tabular}{|l|l|l|l|l|l|l|l|l|}
\hline 1 & 2 & 3 & 4 & 5 & 6 & 7 & 8 & 9 \\
\hline
\end{tabular}

The sight of this picture is for me...

\begin{tabular}{r|l|l|l|l|l|l|l|l|l|l} 
Not at all entertaining & 1 & 2 & 3 & 4 & 5 & 6 & 7 & 8 & 9 & Very entertaining \\
Not at all disturbing & 1 & 2 & 3 & 4 & 5 & 6 & 7 & 8 & 9 & Very disturbing \\
\cline { 2 - 12 } Not at all distressing & 1 & 2 & 3 & 4 & 5 & 6 & 7 & 8 & 9 & Very distressing
\end{tabular}

Overall, this picture makes me feel...

\begin{tabular}{c|c|c|c|c|c|c|c|c|c|c} 
Very sad & 1 & 2 & 3 & 4 & 5 & 6 & 7 & 8 & 9 & Very happy \\
\cline { 2 - 10 } Very bad & 1 & 2 & 3 & 4 & 5 & 6 & 7 & 8 & 9 & Very good
\end{tabular}


Appendix 13: Pictures in advertising - Negative mood condition (follow-up study A)

Please take a moment to look at this picture and imagine in as much detail as possible what the life of this dog must be like. Next, in the space provided below, please reflect on your current feelings and attitudes as you contemplate this image.

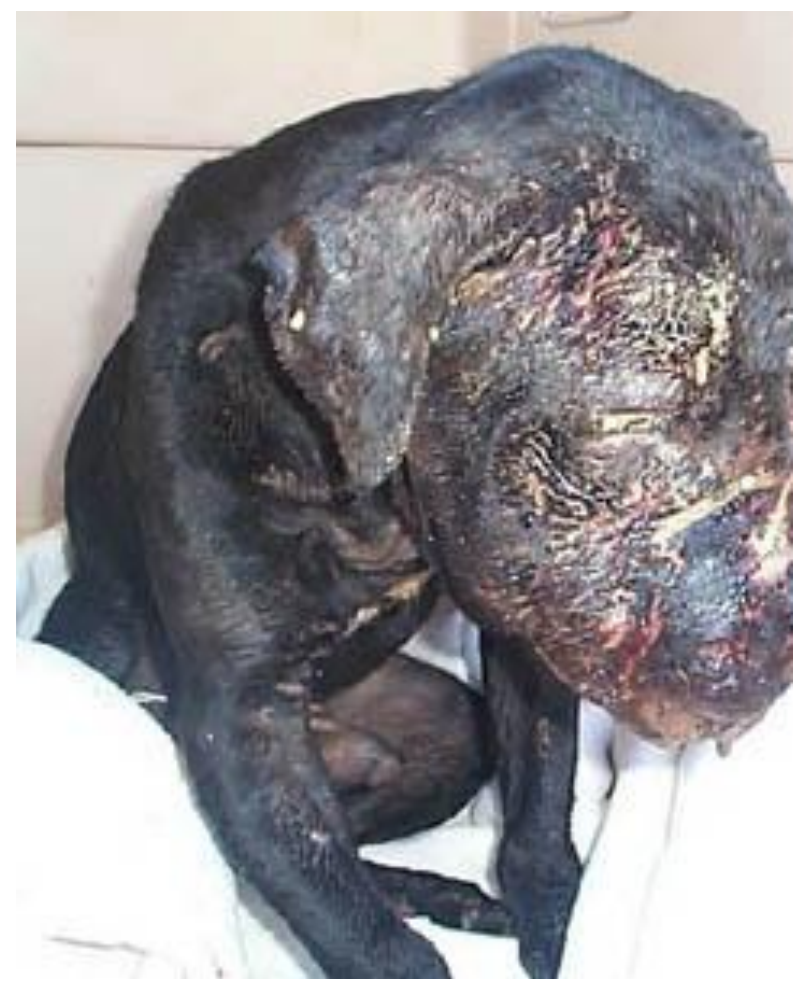

I imagine that the life of this animal is...

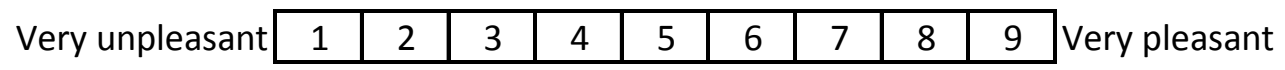

The sight of this picture is for me...

\begin{tabular}{r|l|l|l|l|l|l|l|l|l|l} 
Not at all entertaining & 1 & 2 & 3 & 4 & 5 & 6 & 7 & 8 & 9 & Very entertaining \\
\cline { 2 - 14 } Not at all disturbing & 1 & 2 & 3 & 4 & 5 & 6 & 7 & 8 & 9 & Very disturbing \\
\cline { 2 - 12 } Not at all distressing & 1 & 2 & 3 & 4 & 5 & 6 & 7 & 8 & 9 & Very distressing
\end{tabular}

Overall, this picture makes me feel...

\begin{tabular}{c|c|c|c|c|c|c|c|c|c|l} 
Very sad & 1 & 2 & 3 & 4 & 5 & 6 & 7 & 8 & 9 & Very happy \\
\cline { 2 - 9 } Very bad & 1 & 2 & 3 & 4 & 5 & 6 & 7 & 8 & 9 & Very good
\end{tabular}


Appendix 14: Rosenberg's (1965) scale of state self-esteem (follow up study A)

Instructions: Circle the number under each item that most closely approximates how you feel about yourself right now, that is, at the present moment. Circle only one number per item.

1. Right now I feel that I am a person of worth, at least on an equal basis with others. $\begin{array}{llllllllllll}\text { not at all like me } & 1 & 2 & 3 & 4 & 5 & 6 & 7 & 8 & 9 & 10 & \text { very much like me }\end{array}$

2. Right now I feel that I have a number of good qualities. $\begin{array}{llllllllllll}\text { not at all like me } & 1 & 2 & 3 & 4 & 5 & 6 & 7 & 8 & 9 & 10 & \text { very much like me }\end{array}$

3. Right now I am inclined to feel that I am a failure. $\begin{array}{llllllllllll}\text { not at all like me } & 1 & 2 & 3 & 4 & 5 & 6 & 7 & 8 & 9 & 10 & \text { very much like me }\end{array}$ 4. Right now I feel that I am able to do things as well as most other people. $\begin{array}{llllllllllll}\text { not at all like me } & 1 & 2 & 3 & 4 & 5 & 6 & 7 & 8 & 9 & 10 & \text { very much like me }\end{array}$

5. Right now I feel that I do not have much to be proud of. $\begin{array}{llllllllllll}\text { not at all like me } & 1 & 2 & 3 & 4 & 5 & 6 & 7 & 8 & 9 & 10 & \text { very much like me }\end{array}$ 6. Right now I have a positive attitude toward myself. $\begin{array}{llllllllllll}\text { not at all like me } & 1 & 2 & 3 & 4 & 5 & 6 & 7 & 8 & 9 & 10 & \text { very much like me }\end{array}$ 7. Right now I am satisfied with myself. $\begin{array}{llllllllllll}\text { not at all like me } & 1 & 2 & 3 & 4 & 5 & 6 & 7 & 8 & 9 & 10 & \text { very much like me }\end{array}$ 8. Right now I wish I could have more respect for myself. $\begin{array}{llllllllllll}\text { not at all like me } & 1 & 2 & 3 & 4 & 5 & 6 & 7 & 8 & 9 & 10 & \text { very much like me }\end{array}$ 9. I certainly feel useless right now. $\begin{array}{llllllllllll}\text { not at all like me } & 1 & 2 & 3 & 4 & 5 & 6 & 7 & 8 & 9 & 10 & \text { very much like me }\end{array}$ 10. Right now I think that I am no good at all. $\begin{array}{llllllllllll}\text { not at all like me } & 1 & 2 & 3 & 4 & 5 & 6 & 7 & 8 & 9 & 10 & \text { very much like me }\end{array}$ 
Appendix 15: Word Integration Task - Control condition (follow up study B)

\section{Word Integration Task}

Instructions: Please direct your attention to the examples below. Each example offers 3 stimulus words. The goal of this exercise is to generate a fourth word, which, when combined with each of the 3 stimulus words, would result in word pairs that are a common compound word or phrase. There can be only one correct answer per word problem. [Note: There is no time limit for this exercise, but please spend no more than 5-6 minutes on the task.]

Example 1: cottage/swiss/cake

$\rightarrow$ Answer: $\underline{\text { cheese }}$ as in cottage cheese, swiss cheese, cheese cake

Example 2: cream/skate/water

$\rightarrow$ Answer: $\underline{\text { ice }}$ as in ice cream, ice skate, ice water

Example 3: show/life/row

$\rightarrow$ Answer: $\underline{\text { boat }}$ as in boat show, life boat, row boat

1. flake/mobile/cone $\rightarrow$

2. safety/cushion/point $\rightarrow$

3. fish/mine/rush $\rightarrow$

4. high/district/house $\rightarrow$

5. river/note/account $\rightarrow$

6. print/berry/bird $\rightarrow$

7. cadet/capsule/ship $\rightarrow$

8. fur/rack/tail $\rightarrow$

9. hound/pressure/shot $\rightarrow$

10. basket/eight/snow $\rightarrow$

Flip page over when ready to move on. 
For how many word problems did you provide an answer?

$\rightarrow$ I provided an answer for of the 10 problems.

How many of your answers do you think are correct?

$\rightarrow$ I think that of my answers are correct.

Overall, how well do you think you did on this task? (circle a number)

$\rightarrow$ I think I did...

\begin{tabular}{c|c|c|c|c|c|c|}
\hline 1 & 2 & 3 & 4 & 5 & 6 & 7 \\
\hline $\begin{array}{c}\text { veasonably } \\
\text { well }\end{array}$ \\
poorly
\end{tabular}

If you were to guess, how does your performance fare against that of others? (check one)

$\rightarrow$ My performance places me in the __ Top third of respondents Middle third of respondents Bottom third of respondents

How difficult did you find the task? (circle a number)

$\rightarrow$ I found the task...

\begin{tabular}{|c|c|c|c|c|c|c|}
\hline 1 & 2 & 3 & 4 & 5 & 6 & 7 \\
\hline $\begin{array}{c}\text { not at all } \\
\text { difficult }\end{array}$ & \multicolumn{6}{c|}{$\begin{array}{c}\text { extremely } \\
\text { difficult }\end{array}$} \\
\end{tabular}


Appendix 16: Word Integration Task - Threat condition (follow up study B)

\section{Word Integration Task}

Instructions: Please direct your attention to the examples below. Each example offers 3 stimulus words. The goal of this exercise is to generate a fourth word, which, when combined with each of the 3 stimulus words, would result in word pairs that are a common compound word or phrase. There can be only one correct answer per word problem. [Note: There is no time limit for this exercise, but please spend no more than 5-6 minutes on the task.]

Example 1: cottage/swiss/cake

$\rightarrow$ Answer: $\underline{\text { cheese }}$ as in cottage cheese, swiss cheese, cheese cake

Example 2: cream/skate/water

$\rightarrow$ Answer: $\underline{\text { ice }}$ as in ice cream, ice skate, ice water

Example 3: show/life/row

$\rightarrow$ Answer: $\underline{\text { boat }}$ as in boat show, life boat, row boat

1. shadow/chart/drop $\rightarrow$

2. pet/bottom/garden $\rightarrow$

3. artist/hatch/route $\rightarrow$

4. control/place/rate $\rightarrow$

5. nose/stone/bear $\rightarrow$

6. child/scan/wash $\rightarrow$

7. home/arm/room $\rightarrow$

8. pea/shell/chest $\rightarrow$

9. roll/bean/fish $\rightarrow$

10. cry/front/ship $\rightarrow$

Flip page over when ready to move on. 
For how many word problems did you provide an answer?

$\rightarrow$ I provided an answer for of the 10 problems.

How many of your answers do you think are correct?

$\rightarrow$ I think that of my answers are correct.

Overall, how well do you think you did on this task? (circle a number)

$\rightarrow$ I think I did...

\begin{tabular}{c|c|c|c|c|c|c|}
\hline 1 & 2 & 3 & 4 & 5 & 6 & 7 \\
\hline $\begin{array}{c}\text { veasonably } \\
\text { well }\end{array}$ \\
poorly
\end{tabular}

If you were to guess, how does your performance fare against that of others? (check one)

$\rightarrow$ My performance places me in the __ Top third of respondents Middle third of respondents Bottom third of respondents

How difficult did you find the task? (circle a number)

$\rightarrow$ I found the task...

\begin{tabular}{|c|c|c|c|c|c|c|}
\hline 1 & 2 & 3 & 4 & 5 & 6 & 7 \\
\hline $\begin{array}{c}\text { not at all } \\
\text { difficult }\end{array}$ & \multicolumn{6}{c|}{$\begin{array}{c}\text { extremely } \\
\text { difficult }\end{array}$} \\
\end{tabular}


Appendix 17: Peterson \& Sauber's (1983) mood short form (follow up study B)

Instructions: For each statement below, please circle one number to indicate how much you agree or disagree with the statement.

1) Currently, I am in a good mood.

\begin{tabular}{c|c|c|c|c|}
\hline 1 & 2 & 3 & 4 & 5 \\
\hline $\begin{array}{l}\text { Strongly } \\
\text { agree }\end{array}$ & \multicolumn{4}{c}{$\begin{array}{c}\text { Strongly } \\
\text { disagree }\end{array}$} \\
\end{tabular}

2) As I answer these questions I feel cheerful.

\begin{tabular}{c|c|c|c|c|}
\hline 1 & 2 & 3 & 4 & 5 \\
\hline $\begin{array}{l}\text { Strongly } \\
\text { agree }\end{array}$
\end{tabular}

3) For some reason, I am not very comfortable right now.

\begin{tabular}{c|c|c|c|c|}
\hline 1 & 2 & 3 & 4 & 5 \\
\hline $\begin{array}{l}\text { Strongly } \\
\text { agree }\end{array}$ & \multicolumn{4}{c}{$\begin{array}{c}\text { Strongly } \\
\text { disagree }\end{array}$} \\
\hline
\end{tabular}

4) At this moment I feel edgy or irritable.

\begin{tabular}{|c|c|c|c|c|}
\hline 1 & 2 & 3 & 4 & 5 \\
\hline $\begin{array}{l}\text { Strongly } \\
\text { agree }\end{array}$ & \multicolumn{3}{c}{$\begin{array}{c}\text { Strongly } \\
\text { disagree }\end{array}$}
\end{tabular}


Appendix 18: Big Brothers Big Sisters Survey - Neutral condition (follow up study B)

The Big Brothers Big Sisters Survey

Instructions: This study intends to test a communication campaign by the Big Brothers Big Sisters foundation. Please read the communication on the next page carefully. 


\section{Big Brothers Big Sisters}

Little Moments. Big Magic."

Big Brothers Big Sisters is the oldest, largest and most effective youth mentoring organization in the United States. We have been the leader in one-to-one youth service for more than a century, developing positive relationships that have a direct and lasting impact on the lives of young people. Big Brothers Big Sisters mentors children, ages 6 through 18, in communities across the country - including yours.

The Big Brothers Big Sisters mission is to help children reach their potential through professionally supported, one-to-one relationships with mentors that have a measurable impact on youth.

\section{Our Mentoring Programs Work}

National research has shown that positive relationships between youth and their Big Brothers and Big Sisters mentors have a direct and measurable impact on children's lives. By participating in our youth mentoring programs, Little Brothers and Sisters are:

- $\quad$ More confident in their schoolwork performance

- $\quad$ Able to get along better with their families

- $\quad 46 \%$ less likely to begin using illegal drugs

- $\quad 27 \%$ less likely to begin using alcohol

- $\quad 52 \%$ less likely to skip school.

You, too, can make a difference. Please donate either time or money to help us reach more children in need. Both means of assistance are just as precious to us. Thank you. 
Instructions: Imagine that you were to commit help to the Big Brothers Big Sisters foundation either in the form of money or time. Knowing that both options below are equally valuable to the foundation, what would you personally prefer to do? (check one box below to indicate your relative preference)

Option A: Donate $\$ 10$.

Option B: Donate 8 hours of my time collating fundraising materials and stuffing envelopes.

$\rightarrow$ I would prefer to donate...

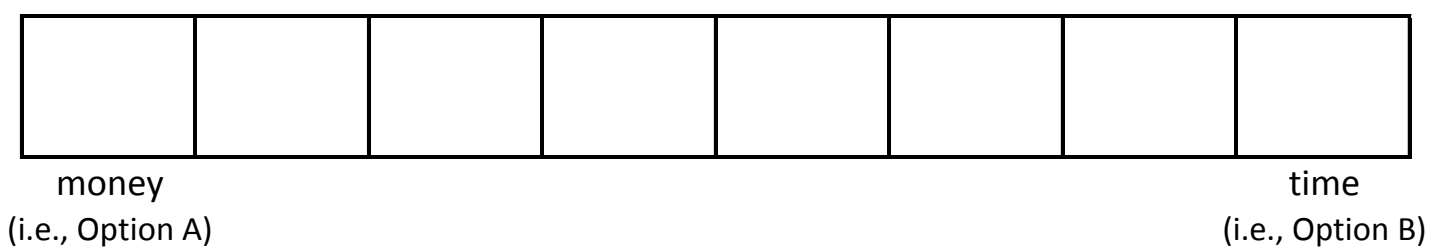


Using the scale below, please indicate...

\begin{tabular}{|c|c|c|c|c|c|c|}
\hline 1 & 2 & 3 & 4 & 5 & 6 & 7 \\
\hline
\end{tabular}

... how enriching would you find it to:

Enter

Number

here

Collate fundraising materials and stuff envelopes

Design \& type fundraising letters

Develop study packets (e.g., create vocabulary lists, outline textbook chapters)

Make a monetary donation

Recruit other volunteers

Solicit donations from potential donors

Tutor a teenager

Update a database with names of potential donors

... how fulfilling would you find it to:

Enter

Number

here

Collate fundraising materials and stuff envelopes

Design \& type fundraising letters

Develop study packets (e.g., create vocabulary lists, outline textbook chapters)

Make a monetary donation

Recruit other volunteers

Solicit donations from potential donors

Tutor a teenager

Update a database with names of potential donors 
Recall of the scale:

\begin{tabular}{|c|c|c|c|c|c|c|}
\hline 1 & 2 & 3 & 4 & 5 & 6 & 7 \\
not at all
\end{tabular}

... how rewarding would you find it to:

Enter

Number

here

Collate fundraising materials and stuff envelopes

Design \& type fundraising letters

Develop study packets (e.g., create vocabulary lists, outline textbook chapters)

Make a monetary donation

Recruit other volunteers

Solicit donations from potential donors

Tutor a teenager

Update a database with names of potential donors

... how satisfying would you find it to:

Enter

Number

here

Collate fundraising materials and stuff envelopes

Design \& type fundraising letters

Develop study packets (e.g., create vocabulary lists, outline textbook chapters)

Make a monetary donation

Recruit other volunteers

Solicit donations from potential donors

Tutor a teenager

Update a database with names of potential donors 
Recall of the scale:

\begin{tabular}{|c|c|c|c|c|c|c|}
\hline 1 & 2 & 3 & 4 & 5 & 6 & 7 \\
\hline
\end{tabular}

... how uplifting would you find it to:

Enter

Number

here

Collate fundraising materials and stuff envelopes

Design \& type fundraising letters

Develop study packets (e.g., create vocabulary lists, outline textbook chapters)

Make a monetary donation

Recruit other volunteers

Solicit donations from potential donors

Tutor a teenager

Update a database with names of potential donors 
Appendix 19: Big Brothers Big Sisters Survey - Repair condition (follow up study B)

The Big Brothers Big Sisters Survey

Instructions: This study intends to test a communication campaign by the Big Brothers Big Sisters foundation. Please read the communication on the next page carefully. 


\section{Big Brothers Big Sisters}

Little Moments. Big Magic."

Big Brothers Big Sisters is the oldest, largest and most effective youth mentoring organization in the United States. We have been the leader in one-to-one youth service for more than a century, developing positive relationships that have a direct and lasting impact on the lives of young people. Big Brothers Big Sisters mentors children, ages 6 through 18, in communities across the country - including yours.

The Big Brothers Big Sisters mission is to help children reach their potential through professionally supported, one-to-one relationships with mentors that have a measurable impact on youth.

\section{Our Mentoring Programs Work}

National research has shown that positive relationships between youth and their Big Brothers and Big Sisters mentors have a direct and measurable impact on children's lives. By participating in our youth mentoring programs, Little Brothers and Sisters are:

- $\quad$ More confident in their schoolwork performance

- $\quad$ Able to get along better with their families

- $\quad 46 \%$ less likely to begin using illegal drugs

- $\quad 27 \%$ less likely to begin using alcohol

- $\quad 52 \%$ less likely to skip school.

You, too, can make a difference. Please donate either time or money to help us reach more children in need. Both means of assistance are just as precious to us. Thank you. 
Instructions: Imagine that you were to commit help to the Big Brothers Big Sisters foundation either in the form of money or time. Knowing that both options below are equally valuable to the foundation, what would you personally prefer to do? (check one box below to indicate your relative preference)

Option A: Donate $\$ 10$.

Option B: Donate 8 hours of my time tutoring children with homework.

$\rightarrow$ I would prefer to donate...

\begin{tabular}{l|l|l|l|l|l|l|}
\hline & & & & & & \\
\hline $\begin{array}{c}\text { money } \\
\text { (i.e., Option A) }\end{array}$ & (i.e., Option B)
\end{tabular}


Using the scale below, please indicate...

\begin{tabular}{|c|c|c|c|c|c|c|}
\hline 1 & 2 & 3 & 4 & 5 & 6 & 7 \\
\hline
\end{tabular}

... how enriching would you find it to:

Enter

Number

here

Collate fundraising materials and stuff envelopes

Design \& type fundraising letters

Develop study packets (e.g., create vocabulary lists, outline textbook chapters)

Make a monetary donation

Recruit other volunteers

Solicit donations from potential donors

Tutor a teenager

Update a database with names of potential donors

... how fulfilling would you find it to:

Enter

Number

here

Collate fundraising materials and stuff envelopes

Design \& type fundraising letters

Develop study packets (e.g., create vocabulary lists, outline textbook chapters)

Make a monetary donation

Recruit other volunteers

Solicit donations from potential donors

Tutor a teenager

Update a database with names of potential donors 
Recall of the scale:

\begin{tabular}{|c|c|c|c|c|c|c|}
\hline 1 & 2 & 3 & 4 & 5 & 6 & 7 \\
not at all
\end{tabular}

... how rewarding would you find it to:

Enter

Number

here

Collate fundraising materials and stuff envelopes

Design \& type fundraising letters

Develop study packets (e.g., create vocabulary lists, outline textbook chapters)

Make a monetary donation

Recruit other volunteers

Solicit donations from potential donors

Tutor a teenager

Update a database with names of potential donors

... how satisfying would you find it to:

Enter

Number

here

Collate fundraising materials and stuff envelopes

Design \& type fundraising letters

Develop study packets (e.g., create vocabulary lists, outline textbook chapters)

Make a monetary donation

Recruit other volunteers

Solicit donations from potential donors

Tutor a teenager

Update a database with names of potential donors 
Recall of the scale:

\begin{tabular}{|c|c|c|c|c|c|c|}
\hline 1 & 2 & 3 & 4 & 5 & 6 & 7 \\
\hline
\end{tabular}

... how uplifting would you find it to:

Enter

Number

here

Collate fundraising materials and stuff envelopes

Design \& type fundraising letters

Develop study packets (e.g., create vocabulary lists, outline textbook chapters)

Make a monetary donation

Recruit other volunteers

Solicit donations from potential donors

Tutor a teenager

Update a database with names of potential donors 


\section{References}

American Association of Fundraising Counsel Press release (2006) available at http://www.aafrc.org/press_releases/trustreleases/0606_PR.pdf.

Anderson, John R. and Gordon H. Bower (1973), Human Associative Memory, New York, NY: John Wiley \& Sons.

Andreoni, James (2004), "Public Goods Experiments Without Confidentiality: A Glimpse Into Fund-Raising," Journal of Public Economics, 88 (7-8) (March), 1605-23.

Baron, Reuben M. and David A. Kenny (1986), “The Moderator-Mediator Variable Distinction in Social Psychological Research: Conceptual, Strategic and Statistical Considerations," Journal of Personality and Social Psychology, 51 (6), 1173-82.

Batson, Daniel C. (1987), "Pro-Social Motivation: Is It Ever Truly Altruistic?" Advances in Experimental Social Psychology, 20, 65-122.

Bowden, E.M. and Jung-Beeman, M. (2003), "Normative Data for 144 Compound Remote Associate Problems," Behavioral Research Methods, Instrumentation, and Computers, 35, 634-39.

Brendl, Miguel, Arthur B. Markman and Claude Messner (2003), "The Devaluation Effect: Activating a Need Devalues Unrelated Objects," Journal of Consumer Research, 29 (March), 463-73.

Brinol, Pablo and Richard E. Petty (2003), "Overt Head Movements and Persuasion: A Self-Validation Analysis," Journal of Personality and Social Psychology, 84 (6), 1123-39.

Carstensen, Laura L. (1995), "Evidence for a Life-Span Theory of Socioemotional Selectivity," Current Directions in Psychological Science, 4, 151-56.

Carstensen, Laura L., Derek M. Isaacowitz, and Susan T. Charles (1999), "Taking Time Seriously: A Theory of Socioemotional Selectivity," American Psychologist, 54 (March), 165-81.

Cialdini, Robert B., Mark Schaller, Donald Houlihan, Kevin Aips, Jim Fultz, and Arthur L. Beaman (1987), "Empathy-Based Helping: Is It Selflessly or Selfishly Motivated?" Journal of Personality and Social Psychology, 52 (4), 749-58.

Clary, E. Gil, Mark Snyder, Robert D. Ridge, John Copeland, Arthur A. Stukas, Julie Haugen and Peter Miene (1998), "Understanding and Assessing the Motivation of Volunteers: A Functional Approach," Journal of Personality and Social Psychology, 74 (6), (June), 1516-30. 
Crocker, Jennifer, Riia K. Luhtanen, M. Lynne Cooper, and Alexandra Bouvrette (2003), "Contingencies of Self-Worth in College Students: Theory and Measurement," Journal of Personality and Social Psychology, 85 (5), 894-908.

DeVoe, Sanford E. and Jeffrey Pfeiffer (2007), "When Time is Money: The Effect of Hourly Payment on the Evaluation of Time," Organizational Behavior \& Human Decision Processes, 104 (1), 1-13.

Ferraro, Rosellina, Baba Shiv and James R. Bettman (2005), "Let Us Eat and Drink, for Tomorrow We Shall Die: Effects of Mortality Salience and Self-Esteem on SelfRegulation in Consumer Choice," Journal of Consumer Research, 32 (June), 65-75.

Foa, E. B., and Foa, U. G. (1980), "Resource theory: Interpersonal behavior in exchange," In Gergen, K. J., Greenberg, M. S. and Willis, R. H. (Eds.), Social exchange: Advances in theory and research, (pp. 77-102). New York: Plenum.

Gao, L., Wheeler, C. and Shiv, B. (2007, under review),’The 'Shaken Self': Product Choices as a Means of Restoring Self-View Confidence."

Harbaugh, William T. (1998a), "The Prestige Motive for Making Charitable Transfers," American Economic Review, Papers and Proceedings, 88 (2) (May), 277-82.

Harbaugh, William T. (1998b), "What Do Donations Buy?” Journal of Public Economics, 67 (2) (February), 269-84.

Heatherton, Todd F. and Janet Polivy (1991), "Development and Validation of a Scale for Measuring State Self-Esteem," Journal of Personality and Social Psychology, 60 (6), 895-910.

Houle, Barbara J., Brad J. Sagarin, and Martin F. Kaplan (2005), “A Functional Approach to Volunteerism: Do Volunteer Motives Predict Task Preference?" Basic and Applied Social Psychology, 27 (4), 337-44.

Independent Sector (2001), Report available at http://www.independentsector.org/PDFs/GV01keyfind.pdf

Jonas, Eva, Jeff Schimel, Jeff Greenberg and Tom Pyszczynski (2002), “The Scrooge Effect: Evidence that Mortality Salience Increases Prosocial Attitudes and Behavior," Personality and Social Psychology Bulletin, 28, 1342-53.

Kottasz, Rita (2004), "How Should Charitable Organizations Motivate Young Professionals to Give Philanthropically?" International Journal of Nonprofit and Voluntary Sector Marketing, 9 (February), 9-27.

Liu, Wendy and Jennifer Aaker (2008), "The Happiness of Giving: The Time-Ask Effect," Forthcoming, Journal of Consumer Research. 
Loewenstein, George, Duane Read, and Roy Baumeister (2003), Time and Decision: Economic and Psychological Perspectives on Intertemporal Choice, New York, NY: Russell Sage Foundation.

Lowenstein, George (1987), "Anticipation and the Valuation of Delayed Consumption," Economic Journal, 97 (September), 666-84.

Olson, Michael A., Russell H. Fazio, and Anthony D. Hermann (2007), "Reporting Tendencies Underlie Discrepancies Between Implicit and Explicit Measures of Self-Esteem," Journal of Psychological Science, 18 (4), 287-91.

Peterson, R and Sauber, M. (1983), “A mood scale for survey research,” In: Murphy, P, Darden, W, Monroe, K and Dillon, W, Editors, 1983. Proceedings of the American Marketing Association Educator's Conference, American Marketing Association, Chicago, IL, pp. 409-414.

Reed II, Americus, Karl Aquino, and Eric Levy, (2007a), "Moral Identity and Judgments of Charitable Behaviors," Forthcoming, Journal of Marketing, 71 (January), 1-31.

Reed II, Americus, Karl Aquino, and Eric Levy, (2007b), “A Social Identity Perspective on Giving Time vs. Money," Working paper.

Robins, Richard W., Holly M. Hendin and Kali H. Trzesniewski (2001), "Measuring Global Self-Esteem: Construct Validation of a Single-Item Measure and the Rosenberg SelfEsteem Scale," Personality and Social Psychology Bulletin, 27, 151-61.

Rosenberg, M. (1965), Society and the Adolescent Self-Image. Princeton, NJ: Princeton University Press.

Rothbart, M. K. (1994), "Emotional development: Changes in reactivity and selfregulation," in P. Ekman \& R. J. Davidson (Eds.), "The nature of emotion: Fundamental questions" (pp. 369-372). Oxford, England: Oxford University Press.

Schwarz, Norbert and Gerald Clore (1996), "Feelings and Phenomenal Experiences," Social Psychology: Handbook of Basic Principles, ed. T. Higgins and A. Kruglanski, New York, NY: Guilford, 433-65.

Sherman, David K., and Geoffrey L. Cohen (2002), "Accepting Threatening Information: Self-Affirmation and the Reduction of Defensive Biases," Current Directions in Psychological Science, 11, 119-23.

Sherman, David K., and Geoffrey L. Cohen (2006), "The Psychology of SelfDefense: Self-Affirmation theory," in Advances in Experimental Social Psychology, ed. M. P. Zanna, San Diego, CA: Academic Press, 38, 183-242. 
Small, Deborah A., George Loewenstein, and Paul Slovic (2007), "Sympathy and Callousness: The Impact of Deliberative Thought on Donations to Identifiable and Statistical Victims," Organizational Behavior and Human Decision Processes, 102 (March), 143-53.

Sobel, Michael E. (1982) "Asymptotic Intervals for Indirect Effects in Structural Equations Models," in Sociological Methodology, ed. S. Leinhart, San Francisco: JosseyBass, 290-312.

Steele, Claude M. (1988), "The Psychology of Self-Affirmation: Sustaining the Integrity of the Self," in Berkowitz, L. (ed.), Advances in Experimental Social Psychology, 21, 261-302.

Steele, Claude M. and Thomas J. Liu (1983), "Dissonance Processes as SelfAffirmation," Journal of Personality and Social Psychology, 45 (1), 5-19.

Steele, Claude M., Steven J. Spencer, and Michael Lynch (1993), "Self-Image Resilience and Dissonance: The Role of Affirmational Resources," Journal of Personality and Social Psychology, 64 (6), 885-96.

Tajfel, Henri (1981), Human Groups and Social Categories, Cambridge: Cambridge University Press.

Tesser, Abraham and David P. Cornell (1991), "On the Confluence of Self Processes," Journal of Experimental Social Psychology, 27 (6), 501-26.

US Department of Labor (2007), "Volunteering in the United States," http://www.bls.gov/news.release/volun.nr0.htm.

Van Boven, Leaf and Thomas Gilovich (2003), "To Do or To Have: That is the Question,” Journal of Personality and Social Psychology, 85 (6), 1193-1202.

Vohs, Kathleen D., Nicole L. Mead, \& Miranda R. Goode (2006), “The Psychological Consequences of Money," Science, 314, 1154 - 56.

Watson, David, Lee Anna Clark, and Auke Tellegen (1988), "Development and Validation of Brief Measures of Positive and Negative Affect: The PANAS Scales," Journal of Personality and Social Psychology, 54 (6) (June), 1063-70.

West, Lori A. (2004), "Non-Profits Face Funding Pressures," Journal of Accountancy, (Sept), 1-2.

Willis, Bob and Shobhana Chandra (2008), "U.S. Economy: Drop in Retail Sales Signals Recession," http://bloomberg.com/apps/news?pid=20601087\&sid=a.vpIoQPaOjI\&refer=home. 
White, Katherine and Darrin R. Lehman (2005), "Looking on the Bright Side: Downward Counterfactual Thinking in Response to Negative Life Events," Personality and Social Psychology Bulletin, 31 (10), 1413-24.

Wilson, John (2000), "Volunteering," Annual Review of Sociology, 26, 215-40.

Wilson, John and Marc Musick (1997), "Who cares? Toward an Integrated Theory of Volunteer Work," American Sociological Review, 62 (October), 694-713.

Zauberman, Gal and John G. Lynch, Jr. (2005), "Resource Slack and Discounting of Future Time versus Money," Journal of Experimental Psychology: General, 134 (Feb), 2337. 